\title{
Modelling of beam response for progressive collapse analysis
}

\section{ABSTRACT}

A fundamental aspect of the progressive collapse behaviour of building structures is the response of axially restrained beams following partial or total loss of the loadbearing capacity of a supporting member. Owing to the various complex effects involved such as material and geometric nonlinearity, advanced numerical approaches tend to be the most effective tools for modelling performance. Such approaches, however, lack the simplicity needed for common use and may provide only limited capability for understanding structural behaviour. For such purposes, more limited analysis approaches that can address adequately the basic features of performance are likely to be more productive. One such method for modelling the response of axially restrained steel and composite beams following column loss is presented in this paper. The method involves explicit modelling of the connection behaviour and employs conventional structural analysis principles to describe beam performance using accessible spreadsheet calculations. Following careful verification against detailed numerical analyses and validation against available experimental results, the proposed method is deemed capable of modelling the various complex features of response with excellent accuracy. Therefore, it may form a promising advance in studying and understanding the basic mechanics of the problem.

Keywords: analytical method; arching action; catenary action; column loss; composite structures; robustness

* Corresponding author: 
Email:p.stylianidis@outlook.com

\section{Introduction}

The last two decades have seen an increasing growth of general interest into the behaviour of building structures in progressive collapse; this has been stimulated to a considerable extent by successive notable incidents such as the collapses of the Murrah Building in 1996 and the WTC Twin Towers in 2001. However, progressive collapse and the associated property of robustness has been recognised in some quarters for many decades, with its origin being traditionally dating back to the well-known collapse of the Ronan Point building in 1968. Most of the current formal design approaches to assessing or increasing resistance to progressive collapse essentially originate as a direct consequence of the work conducted in the UK following the Ronan Point collapse [1]. These approaches however, have tended to be of a prescriptive nature since they only impose certain conditions on the basis that their inclusion will ensure better performance than had they been omitted, thereby offering limited capability for assessing the actual level of robustness possessed by the structure.

One such common approach for addressing progressive collapse in steel and composite buildings is through the provision of a suitable level of tying resistance in the frame components. Tying requirements aim at enhancing structural robustness by increasing the degrees of continuity, ductility and load transfer capacity. Various forms of the tie-force method are addressed in most design codes such as the Eurocodes [2] and recent US Guidelines to robustness [3, 4]. By general consensus however, its suitability as a measure of resistance to progressive collapse is somewhat doubtful [5]. Relevant studies [6-10] have demonstrated that tying alone does not account for all the mechanisms likely to be necessary to arrest collapse, while the connection deformations required in order to develop catenary action - i.e. the load carrying mechanism associated with tying - are often considerably greater than the available deformation capacities.

As the interest in the more scientific treatment of the topic increases, so the need for a sound understanding of the mechanisms by which progressive collapse is triggered becomes more important. Research studies during the past decade have been directed at meeting this need by seeking to move the design basis from prescriptive requirements to approaches based on understanding, modelling and quantitative assessment. Much of the recent work conducted worldwide [e.g. 6-15] is based on the 'alternative load path' concept. Most frequently, the alternative load path analysis considers the consequences of a threat-independent sudden column removal on the surrounding structure. It may incorporate the essential features of the problem such as dynamic effects, material and geometric nonlinear effects and interaction between the 
various structural and non-structural components. Therefore, the alternative load path approach offers the

advantage of demonstrating the actual structural behaviour in a quantitative manner.

The level of structural analysis used to examine the behaviour of the damaged structure may vary from static applications employing elastic theory and dynamic load factors to sophisticated numerical approaches including dynamic effects, second-order geometric effects and inelastic material behaviour [16]. Studies have shown that rather different outcomes result depending on which analysis approach is employed [17, 18]. Apparently, the more sophisticated the analysis the more representative the results. However, linear static applications have the advantage of being simple to implement, while sophisticated analyses may be extremely demanding in terms of computing capability and therefore unsuitable for routine use. Much of the recent research work on the topic involved the use of such computationally intensive analyses [e.g. 1315]. Although such studies may be useful for identifying specific features of behaviour for further consideration, for the purposes of securing detailed understanding of the structural response and thus making direct quantitative links between cause and effects, more limited approaches are likely to be more productive.

Based on that concept, work at Imperial College London during the past decade has been concerned with the development of an alternative method for implementing the alternate load path approach in a way that all the essential features of the problem are addressed but which does not require unduly complex analysis. The basic framework has been developed by Izzuddin et al. [19] and it is described in Figs. 1 and 2. It permits reduction of the level of structural representation considered in the analysis as described in Fig. 1, with the responses at higher levels being assembled from the responses at lower levels based on a simple multi-level approach. Whatever the level of structural idealisation, only nonlinear static analysis is required with the dynamic effects being accounted for based on an energy-balance concept as described in Fig. 2. For any level of suddenly applied gravity load $\left(P_{n}=\lambda_{n} P_{\mathrm{o}}\right)$, the maximum dynamic displacement $\left(w_{d, n}\right)$ is determined from the nonlinear static response based on the equivalence between the work done by the load and the energy absorbed by the structure as shown in Figs. 2(a) and 2(b). By plotting the suddenly applied gravity loading against the maximum dynamic displacement, a 'pseudo-static' $\left(P-w_{d}\right)$ curve representing the maximum nonlinear dynamic response is obtained as demonstrated in Fig. 2(c). Therefore, the maximum dynamic displacement corresponding to the actual gravity load $P_{\mathrm{o}}$ can be readily determined from the pseudo-static response.

The Imperial College method provides, within a simplified framework, a complete representation of the progressive collapse phenomenon. Essentially, the analysis phase can be limited only to the prediction of 
the nonlinear static responses of the individual beams. Static load-deflection analyses may be conducted

using convenient methods that incorporate whatever degree of sophistication is considered appropriate. Although advanced finite element models may be employed, simplified analytical methods are likely to be more suitable for conducting rapid parametric studies and understanding the mechanics of the problem, provided they are capable of addressing sufficiently the basic features of the behaviour.

The basic features of beam behaviour following column removal are discussed in the next section where it is confirmed that performance depends to a considerable extent on the behaviour of the connections between the beam and its supporting members. A mechanical approach for modelling connection behaviour in progressive collapse, which has been previously devised at Imperial College [20], is briefly described next. Based on that mechanical approach, an analytical method for modelling the response of steel and composite beams using conventional structural analysis principles is developed in the reminder of the paper. It is demonstrated that the new analytical method may effectively address the basic features of behaviour to a similar degree of accuracy as detailed numerical models. This new development streamlines considerably the necessary analyses, thereby making it possible to conduct rapid parametric studies that provide insights into the behaviour of building structures during progressive collapse and facilitates understanding of the mechanics of the problem.

\section{Key features of beam response following column removal}

The double-span mechanism created by two adjacent beams following loss of the intermediate column as illustrated in Fig. 3 represents a simple and commonly used representation of the alternative load path concept for examining beam and connection behaviour. Either the damaged unloaded structure is considered and the gravity loading is then applied, or the intact loaded structure is considered and then notional column removal is performed. Depending on the position of the removed column within the frame, a degree of axial restraint may be provided to simulate interaction with the surrounding structure. The double-span beam approach has been adopted in several recent numerical and experimental studies of progressive collapse where nonlinear static applications were employed [11, 12, 21-26].

Previous studies have shown that the form of behaviour varies depending on the type of the connections employed. Axially restrained beams with semi-rigid or rigid connections suffering column loss exhibit the form of load-deflection response shown in Fig. 4(a) [19, 27], where the corresponding behaviour in the absence of axial restraint is also presented. The figure describes the full range of behaviour independently of any deformation limits that may be imposed by the available ductility of the connections in practice. The 
response comprises various phases, where different mechanisms are mobilised in each phase to resist 1 collapse. Following the initial elastic phase which essentially resembles behaviour under normal loading conditions, the post-elastic response (i.e. beyond point ' $\mathrm{B}$ ' in Fig. 4) is governed by the effects of material and geometric nonlinearity.

As shown in Fig. 3, the 'support' connections are subject to hogging bending moments, whereas the 'midspan' connections are subject to sagging bending moments after column loss. In the absence of axial restraint, the response depends exclusively on the bending moment capacity and rotational stiffness of the connections. In the post-limit phase, the stiffness of the system decreases with decreases in the rotational stiffness of the connections due to material yielding or instability effects. In addition to the bending moments, the connections are subject to axial forces that are generated in the beams due to the effects of geometric nonlinearity in the presence of axial restraint. Various combinations may be seen during the different stages of the response as demonstrated in the typical diagram of Fig. 4(b) [27].

At relatively small deflections, the behaviour may be enhanced by compressive arching action as shown in Fig. 4(a). Both the beam axial compression and the connection bending moments may reach relatively high values during that stage as shown in Fig. 4(b). The compressive arching action may be limited by reduction in the stiffness of the connection compression zone due to instability effects as illustrated in Fig. 3(a). Following a peak in the load carrying capacity (i.e. between points ' $B$ ' and ' $C$ '), the effects of arching action gradually decrease and the beam axial load becomes tensile in the subsequent stages (i.e. beyond point ' $D$ '). While transferring from the compressive arching to the tensile stage, the beam may exhibit an unstable snap-through response until a new stable equilibrium position is adopted. Meanwhile, the peak of the compressive axial load is associated with a neutrally stable compressive arching condition where the load carrying capacity is similar to the corresponding capacity in the absence of axial restraint (i.e. point C).

The same effect arises at the end of the compressive arching stage when the compressive axial load decreases to zero (i.e. point D). In the subsequent tensile stage, any increase in the deflection entails significant increases in the load carrying capacity, as shown in Fig. 4(a), due to the axial tension developed in the beam. As the ratio between the beam tensile force and the connection bending moment increases, the bending moment effects become less significant and connections undergo extensive tensile deformations. At very large deflections (i.e. following point 'E'), prying action in the connections (i.e. between the beam compressive flanges and the supporting members) may be eliminated as illustrated in Fig. 3(b) and tensile catenary action becoming the principal load carrying mechanism. A comprehensive analysis of the behaviour following column removal is provided elsewhere [27]. 
Therefore, some important features of the behaviour are identified:

- Beams may undergo very large deflections, resulting in extensive connection deformations that develop well beyond the elastic range.

- Performance is governed by nonlinear geometric effects.

- In the presence of axial restraint, compressive arching and tensile catenary actions are mobilised.

- The compressive arching and tensile catenary effects depend on the ability of the connections to transmit the axial forces generated in the beams.

- The beam axial forces may develop disproportionally to the connection bending moments during the different stages of the response.

- The support connections of the double-span beam are subject to hogging bending moments whereas the mid-span connections are subject to sagging bending moments. Therefore, they may exhibit quite different responses depending on their type and geometry.

- The connection compressive components may undergo deformation reversal following a decrease in the axial compression towards the end of the compressive arching stage.

- A different form of response develops at very large deflections during the tensile stage when the beams actually exhibit catenary behaviour owing to the absence of prying action in the connections.

It is confirmed that the performance of the connections is of crucial importance for the response of the structures during progressive collapse. Beam behaviour depends to a considerable extent on the ability of the connections to transmit the sorts of loading (i.e. bending moments and axial forces) generated following an initial damage whilst delivering the deformations needed to arrest collapse without exhausting their ductility limits. Therefore, a correct description of the connection behaviour under the sorts of conditions experienced after column removal is fundamental for any realistic analysis.

\section{Modelling of connection behaviour for progressive collapse analysis}

By considering the key features discussed in the previous section, Stylianidis and Nethercot [20] developed a mechanical method for describing the behaviour of bare steel and composite connections during progressive collapse. In the case of a double-span beam condition imposed by column removal, the response is simulated by the spring models shown in Fig. 5, which have been devised based on the concept proposed by Del Savio et al. [28]. Each spring model comprises a set of rigid bars - where each bar is associated with a distinct zone (i.e. tension, compression or shear) of the connection - connected with 
linear springs that model the behaviour of the various connection components and rigid links that transfer 1 the total tensile $\left(F^{T}\right)$ and compressive $\left(F^{C}\right)$ forces to the support.

2

3

4

In the method proposed in [20], each spring is modelled based on a bi-linear force-deformation approximation, where the component characteristics are determined using the principles of EC3 [29] and EC4 [30]. Important features of the behaviour such as material nonlinearity, strain-hardening and deformation reversal are accounted for. However, rather more sophisticated characterisation approaches based on tri-linear or multi-linear approximations may also be adopted.

The proposed method comprises a mechanical approach for assembling the behaviour of the various components to form the overall connection behaviour at each stage of beam response following column removal. In particular, explicit formulae linking the connection deformations - i.e. rotations $\left(\varphi^{\prime}, \varphi\right)$ and horizontal deformations $\left(u^{\prime}, u\right)$ as defined in Fig. 5 - with the connection bending moments $\left(M^{\prime}, M\right)$ and beam axial load $(N)$ are provided as follows:

$$
\begin{gathered}
\varphi^{\prime}=M^{\prime} \alpha_{1}^{\prime}+N z^{\prime} \beta_{1}^{\prime}-\gamma_{1}^{\prime} \\
\varphi=M \alpha_{1}+N z \beta_{1}-\gamma_{1} \\
u^{\prime}=M^{\prime} \alpha_{2}{ }^{\prime}+N z^{\prime} \beta_{2}^{\prime}-\gamma_{2}{ }^{\prime} \\
u=M \alpha_{2}+N z \beta_{2}-\gamma_{2}
\end{gathered}
$$

The parameters $\alpha_{i}, \beta_{i}$ and $\gamma_{i}$ depend on the properties of the connection components and may vary along with variations in the stiffness of the components during the analysis. Full details may be found in [20]. In the present paper, the addition of a note denotes that the quantity is associated with the hogging region (i.e. the region of the support connection).

Any possible combination between the connection bending moments (hogging or sagging) and the beam axial load seen during the compressive arching and tensile catenary stages may be accounted for, with the corresponding different modes of connection deformations being explicitly modelled. Material nonlinearity is considered in a simplified yet reasonably sufficient manner, thus allowing for a complete representation of the full range of the behaviour up to failure. The response may be traced in a step-by-step fashion using only spreadsheet calculations. Failure can be determined by comparing the component deformations with the corresponding deformation limits in each step of the analysis.

\section{Analytical representation of the beam nonlinear static response following column removal}


Based on the axially restrained double-span beam concept, an analytical method for describing the 1 nonlinear static response of bare steel and composite beams following column removal is developed in this

section. Provided the double-span beam structure is symmetric in terms of geometry and loading with respect to the centreline of the removed column as illustrated in Fig. 6(a), the two individual beams exhibit identical independent responses. Therefore, consideration may be given only to half of the structure. Based on this assumption, the unloaded structure in its damaged condition is modelled as shown in Fig. 6(b).

The behaviour of the beam section is considered as linear elastic and therefore it may be described based on the axial and flexural rigidity. Some effects such as yielding and local buckling are likely to develop only in the vicinity of the connections and therefore they may be included in the connection modelling, whereas out-of-plane effects, such as lateral buckling, are ignored. Similarly, the behaviour of the adjacent structure is considered as elastic and, therefore, the effects of axial restraint are modelled by employing a linear elastic boundary spring. The stiffness of the boundary spring may approximately be assumed as the stiffness provided by the structural components in the immediate vicinity of the damaged structure - i.e. the axial stiffness of the beam and the connection on the opposite side of the support connections [8] and/or the flexural stiffness of the intact column sections that support the double-span beam [12]. Alternatively, it may be assessed based on the force-deformation ratio obtained from a linear elastic analysis of the neighbouring structure loaded by axial forces applied in the direction of the double-span beam [11]. However, detailed modelling of the connection behaviour, accounting for the effects of material nonlinearity and the interaction between bending moments and axial forces, is considered. In particular, the connection behaviour is modelled using the mechanical approach described in the previous section [20]. Therefore, the rotational springs shown in Fig. 6(b) actually represent the detailed spring models of Fig. 5.

Two schemes of gravity loading are considered including uniformly distributed load $(q)$ and mid-span point load $(P)$. The internal forces and component deformations developed following the application of the gravity loading are described in Fig. 6(c), where the internal forces are considered to be positive when acting in the illustrated directions. Using conventional structural analysis principles, explicit relationships between the gravity loading ( $q$ or $P$ ) and the beam deflection $(w)$ as well as analytical expressions linking the component forces (i.e. $M^{\prime}, M$ and $N$ ) and deformations (i.e. $\varphi^{\prime}, \varphi$ and $\Delta_{s}$ ) with the gravity loading and beam deflection are derived. The set of those analytical expressions forms an explicit method for describing the complete behaviour. A detailed description of the method is given next.

\subsection{Connection bending moments}


Following column removal, the support connections of the double-span beam are subject to hogging

bending moments $\left(M^{\prime}\right)$ whereas the mid-span connections are subject to sagging bending moments $(M)$ as shown in Fig. 6(c). The bending moment diagram depends both on the connection characteristics and the flexural stiffness of the beam - whereas it may also be influenced by the presence of axial load at relatively large deflections. Composite beams exhibit different behaviour under sagging and hogging bending moments. Under hogging bending moment, the concrete is in tension and it is likely to be cracked, resulting in a reduction in the axial and flexural stiffness of the composite section. Since this may influence performance, the model of Fig. 6(b) is modified as shown in Fig. 7, where the beam component comprises two sections with different stiffness. The uncracked stiffness (i.e. EI, EA) is considered in the region of sagging bending moment and the reduced cracked stiffness (i.e. $E I^{\prime}, E A^{\prime}$ ) is considered in the hogging moment region. The width of the concrete flange may be determined based on the effective breadth approach of EC4 [30]. The nominal distance between zero bending moments may approximately be assumed as constant and determined according to the EC4 simplified approach by treating the double-span beam structure as a single-span beam supported at both ends. The uncracked section modulus can be determined based on the traditional transformed section method with transforming the effective breadth of the concrete flange to an equivalent breadth of steel.

The bending moments and shear forces can be determined based on the stiffness method and the concept of releasing clamped structures. The nodal forces corresponding to the element loads (i.e. $q$ ) of the equivalent clamped structure are defined as described in Fig. 8. The displacement modes of the released structure are shown in Fig. 9. For each uniform section, the final forces are obtained by considering the sum of the nodal forces caused by the deformations shown in Fig. 9 and the equivalent nodal forces defined in Fig. 8:

$$
\left[\begin{array}{c}
-M^{\prime} \\
-M^{0} \\
Q^{0}
\end{array}\right]=\left[\begin{array}{ccc}
\frac{4 E I^{\prime}}{L_{h}} & \frac{2 E I^{\prime}}{L_{h}} & -\frac{6 E I^{\prime}}{L_{h}^{2}} \\
\frac{2 E I^{\prime}}{L_{h}} & \frac{4 E I^{\prime}}{L_{h}} & -\frac{6 E I^{\prime}}{L_{h}^{2}} \\
-\frac{6 E I^{\prime}}{L_{h}^{2}} & -\frac{6 E I^{\prime}}{L_{h}^{2}} & \frac{12 E I^{\prime}}{L_{h}^{3}}
\end{array}\right]\left[\begin{array}{c}
\varphi^{\prime} \\
\varphi^{0} \\
w^{0}
\end{array}\right]+\left[\begin{array}{c}
-\frac{q L_{h}^{2}}{12} \\
\frac{q L_{h}^{2}}{12} \\
-\frac{q L_{h}}{2}
\end{array}\right]
$$




$$
\left[\begin{array}{c}
M^{0} \\
-Q^{0} \\
Q
\end{array}\right]=\left[\begin{array}{cccc}
\frac{4 E I}{L_{s}} & \frac{2 E I}{L_{s}} & \frac{6 E I}{L_{s}^{2}} & -\frac{6 E I}{L_{s}^{2}} \\
\frac{2 E I}{L_{s}} & \frac{4 E I}{L_{s}} & \frac{6 E I}{L_{s}^{2}} & -\frac{6 E I}{L_{s}^{2}} \\
\frac{6 E I}{L_{s}^{2}} & \frac{6 E I}{L_{s}^{2}} & \frac{12 E I}{L_{s}^{3}} & -\frac{12 E I}{L_{s}^{3}} \\
-\frac{6 E I}{L_{s}^{2}} & -\frac{6 E I}{L_{s}^{2}} & -\frac{12 E I}{L_{s}^{3}} & \frac{12 E I}{L_{s}^{3}}
\end{array}\right]\left[\begin{array}{c}
\varphi^{0} \\
\varphi \\
w \\
w^{0} \\
\frac{q L_{s}^{2}}{12} \\
-\frac{q L_{s}}{2} \\
-\frac{q L_{s}}{2}
\end{array}\right]+\left[\begin{array}{c}
-\frac{q L_{s}^{2}}{12} \\
\end{array}\right]
$$

Specifying the exact location of the point of inflection can be rather difficult since it varies along with possible variations in the connection bending moments and the beam axial load during the analysis. Unless it is located very close to either of the connections however, its influence on the bending moment diagram is rather insignificant. Therefore, to simplify the process, a constant point of inflection is considered at the mid-span of the beam (i.e. $L_{h}=L_{s}=L / 2$ ). Based on this assumption, Eqs. (5) and (6) are developed as shown next (where, $Q$ does not need to be further considered and it is excluded from the following set of equations):

$$
\begin{gathered}
M^{\prime}=-\frac{8 E I^{\prime}}{L} \varphi^{\prime}-\frac{4 E I^{\prime}}{L} \varphi^{0}+\frac{24 E I^{\prime}}{L^{2}} w^{0}+\frac{q L^{2}}{48} \\
M^{0}=-\frac{4 E I^{\prime}}{L} \varphi^{\prime}-\frac{8 E I^{\prime}}{L} \varphi^{0}+\frac{24 E I^{\prime}}{L^{2}} w^{0}-\frac{q L^{2}}{48} \\
Q^{0}=-\frac{24 E I^{\prime}}{L^{2}} \varphi^{\prime}-\frac{24 E I^{\prime}}{L^{2}} \varphi^{0}+\frac{96 E I^{\prime}}{L^{3}} w^{0}-\frac{q L}{4} \\
M^{0}=\frac{8 E I}{L} \varphi^{0}+\frac{4 E I}{L} \varphi+\frac{24 E I}{L^{2}} w^{0}-\frac{24 E I}{L^{2}} w-\frac{q L^{2}}{48} \\
M=-\frac{4 E I}{L} \varphi^{0}-\frac{8 E I}{L} \varphi-\frac{24 E I}{L^{2}} w^{0}+\frac{24 E I}{L^{2}} w-\frac{q L^{2}}{48} \\
Q^{0}=-\frac{24 E I}{L^{2}} \varphi^{0}-\frac{24 E I}{L^{2}} \varphi-\frac{96 E I}{L^{3}} w^{0}+\frac{96 E I}{L^{3}} w+\frac{q L}{4}
\end{gathered}
$$

The set of the above expressions does not include the effects of the beam axial load, but those effects may be incorporated by considering the equilibrium conditions. Based on Fig. 10, the following equilibrium equations are obtained for each section: 
By substituting $M^{\prime}$ and $M^{0}$ from Eqs. (7) and (8) respectively into Eq. (13) as well as $M^{0}$ and $M$ from Eqs. (10) and (11) respectively into Eq. (14) and solving each of the resulting equations for $Q^{0}$, the following expressions are obtained:

$$
\begin{aligned}
& Q^{0}=-\frac{24 E I^{\prime}}{L^{2}} \varphi^{\prime}-\frac{24 E I^{\prime}}{L^{2}} \varphi^{0}+\frac{96 E I^{\prime}}{L^{3}} w^{0}-\frac{q L}{4}+\frac{2 N}{L}\left(\frac{w}{2}-Z\right) \\
& Q^{0}=-\frac{24 E I}{L^{2}} \varphi^{0}-\frac{24 E I}{L^{2}} \varphi-\frac{96 E I}{L^{3}} w^{0}+\frac{96 E I}{L^{3}} w+\frac{q L}{4}+\frac{N w}{L}
\end{aligned}
$$

As compared to Eqs. (9) and (12) respectively, the additional components included in Eqs. (15) and (16) represent the effects of the beam axial load.

The shear force at the mid-span of the beam is:

$$
Q^{0}=\frac{q L}{2}+P
$$

By substituting the above expression into Eqs. (15) and (16) and solving the set of the resulting equations for $\varphi^{0}$ and $w^{0}$, the following equations are obtained:

$$
\begin{gathered}
\varphi^{0}=-\frac{1}{2} \varphi^{\prime}-\frac{1}{2} \varphi+\frac{2}{L} w-\frac{q L^{3}}{192 E I}-\frac{3 q L^{3}}{192 E I^{\prime}}-\frac{P L^{2}}{48 E I}-\frac{P L^{2}}{48 E I^{\prime}}+\frac{N w L}{48 E I}+\frac{N L}{24 E I^{\prime}}\left(\frac{w}{2}-Z\right) \\
w^{0}=\frac{L}{8} \varphi^{\prime}-\frac{L}{8} \varphi+\frac{1}{2} w-\frac{q L^{4}}{768 E I}+\frac{3 q L^{4}}{768 E I^{\prime}}-\frac{P L^{3}}{192 E I}+\frac{P L^{3}}{192 E I^{\prime}}+\frac{N w L^{2}}{192 E I}-\frac{N L^{2}}{96 E I^{\prime}}\left(\frac{w}{2}-Z\right)
\end{gathered}
$$

By incorporating the above expressions for $\varphi^{0}$ and $w^{0}$, Eqs. (7) and (11) are developed as shown next: 


$$
\begin{gathered}
M^{\prime}=-\frac{3 E I^{\prime}}{L} \varphi^{\prime}-\frac{E I^{\prime}}{L} \varphi+\frac{4 E I^{\prime}}{L^{2}} w+q \zeta_{1}{ }^{\prime}+P \zeta_{2}{ }^{\prime}+N \zeta_{3}{ }^{\prime} \\
M=-\frac{E I}{L} \varphi^{\prime}-\frac{3 E I}{L} \varphi+\frac{4 E I}{L^{2}} w+q \zeta_{1}+P \zeta_{2}+N \zeta_{3}
\end{gathered}
$$

Where:

$$
\begin{aligned}
& \zeta_{1}{ }^{\prime}=\frac{17 L^{2}}{96}-\frac{E I^{\prime} L^{2}}{96 E I} ; \quad \zeta_{2}{ }^{\prime}=\frac{5 L}{24}-\frac{E I^{\prime} L}{24 E I} ; \quad \zeta_{3}{ }^{\prime}=\frac{E I^{\prime} w}{24 E I}-\frac{5}{12}\left(\frac{w}{2}-\mathrm{Z}\right) \\
& \zeta_{1}=\frac{L^{2}}{32}-\frac{E I L^{2}}{32 E I^{\prime}} ; \quad \zeta_{2}=\frac{5 L}{24}-\frac{E I L}{24 E I^{\prime}} ; \quad \zeta_{3}=\frac{E I}{12 E I^{\prime}}\left(\frac{w}{2}-\mathrm{Z}\right)-\frac{5 w}{24}
\end{aligned}
$$

Finally, by substituting $\varphi^{\prime}$ and $\varphi$ from Eqs. (1) and (2) into Eqs. (20) and (21) and solving the set of resulting equations for $M^{\prime}$ and $M$, the following expressions that link the connection bending moments with the beam deflection, the beam gravity loading and the beam axial load are obtained:

$$
\begin{aligned}
& M^{\prime}=N \kappa^{\prime}+\lambda^{\prime}+q \mu^{\prime}+P v^{\prime} \\
& M=N \kappa+\lambda+q \mu+P v
\end{aligned}
$$

Where:

$$
\begin{aligned}
& \kappa^{\prime}=\kappa_{1} \tau+\kappa_{2} \sigma ; \kappa=\kappa_{1}-\kappa_{2} \\
& \lambda^{\prime}=\lambda_{1} \tau-\lambda_{2} \sigma ; \quad \lambda=\lambda_{1}+\lambda_{2} \\
& \mu^{\prime}=\mu_{1} \tau-\mu_{2} \sigma ; \quad \mu=\mu_{1}+\mu_{2} \\
& v^{\prime}=v_{1} \tau-v_{2} \sigma ; \quad v=v_{1}+v_{2} \\
& \kappa_{1}=\frac{1}{a_{1}{ }^{\prime} \rho}\left(-\beta_{1}{ }^{\prime} z^{\prime}-3 \beta_{1} z+\frac{L \zeta_{3}}{E I}\right) ; \quad \kappa_{2}=\frac{8 E I^{\prime} \beta_{1} z}{L \rho}-\frac{3 E I^{\prime} \zeta_{3}}{\rho E I}+\frac{\zeta_{3}{ }^{\prime}}{\rho} \\
& \lambda_{1}=\frac{1}{\alpha_{1}{ }^{\prime} \rho}\left(\gamma_{1}{ }^{\prime}+3 \gamma_{1}+\frac{4 w}{L}\right) ; \quad \lambda_{2}=\frac{8 E I^{\prime}}{L \rho}\left(\gamma_{1}+\frac{w}{L}\right) \\
& \mu_{1}=\frac{L \zeta_{1}}{\alpha_{1}{ }^{\prime} \rho E I} ; \quad \mu_{2}=\frac{3 E I^{\prime} \zeta_{1}}{\rho E I}-\frac{\zeta_{1}{ }^{\prime}}{\rho} \\
& v_{1}=\frac{L \zeta_{2}}{\alpha_{1}{ }^{\prime} \rho E I} ; \quad v_{2}=\frac{3 E I^{\prime} \zeta_{2}}{\rho E I}-\frac{\zeta_{2}{ }^{\prime}}{\rho}
\end{aligned}
$$


By substituting $M^{\prime}$ and $M$ from Eqs. (22) and (23) into Eq. (24), the following expression that links the beam axial load with the gravity loading and the beam deflection is obtained:

$$
N=\frac{1}{\kappa_{3}}\left(\frac{q L^{2}}{2}-\mu_{3} q+P L-v_{3} P-\lambda_{3}\right)
$$

Where:

$$
\kappa_{3}=\kappa^{\prime}+\kappa+w-Z ; \quad \lambda_{3}=\lambda^{\prime}+\lambda ; \quad \mu_{3}=\mu^{\prime}+\mu ; \quad v_{3}=v^{\prime}+v
$$

\subsection{Axial deformation}

In the presence of axial restraint, the beam section, the axial support and the connections are subject to axial deformations due to changes in the geometry effects. For calculating the beam axial load, detailed representations of those deformations are required. Based on the second-order approximation shown in Fig. 11 , the total axial deformation may be expressed with respect to the beam deflection as $\Delta=w^{2} / 2 L$. Therefore, the following equation may be adopted:

$$
\frac{w^{2}}{2 L}=u^{\prime}+u+\Delta^{\mathrm{a}}+\Delta_{b}
$$

In Eq. (26), $u^{\prime}$ and $u$ represent the horizontal deformations of the support and mid-span connections (Fig. 5), $\Delta^{\mathrm{a}}$ is the sum of the axial deformations of the beam section and the axial support and $\Delta_{b}$ is an additional deformation due to bending of the beam. For consistency, a reference line should be assigned in parallel with the beam longitudinal axis and each of the above deformations should be determined with respect to that line. The reference line may be located at any level of the beam depth. 
The deformations of the connections can be determined based on the connection mechanical approach

described in section 3 [20] using Eqs. (3) and (4). The horizontal deformation of each connection depends on the corresponding rotation and the distance between the connection centre of rotation and the line considered as a reference for assessing the axial deformation of the system. Since the connection rotation depends on the interaction between the applied bending moment and axial load, the sign of the connection horizontal deformation may differ from the sign of the axial load transferred from the beam.

As noted previously, the behaviour of the beam section and the axial support is considered as linear elastic. Therefore, the sum of the axial deformations of these components $\left(\Delta^{\mathrm{a}}\right)$ can be obtained using an effective axial stiffness defined as $K^{\mathrm{a}}=1 /\left(1 / K_{s}+L / E A\right)$ - where $K_{s}$ is the stiffness of the axial support and $E A / L$ is the axial stiffness of the beam section (Fig. 6) - as follows:

$$
\Delta^{\mathrm{a}}=\frac{N}{K^{\mathrm{a}}}
$$

The total axial deformation may also be influenced by the flexural deformation of the beam section. This depends on the level of the line considered as a reference for defining the total axial deformation. As shown in Fig. 12, no additional deformation due to beam bending should be considered when the reference line coincides with the beam neutral axis (i.e. Reference line 1). If any other reference line is adopted however (e.g. Reference line 2), the corresponding flexural deformation of the beam section should be taken into account.

In composite beams, the level of the neutral axis is different in the hogging and sagging moment regions. Therefore, it is not possible to define a specific line in parallel with the longitudinal axis which is not subject to deformation due to beam bending. Provided the reference line coincides with the hogging neutral axis, the corresponding deformation due to sagging bending moment should be taken into account. This may be approximated as follows:

$$
\Delta_{b}=\frac{\mathrm{Z}}{E I} \int_{0}^{L_{s}} M_{x} d x
$$

Based on Fig. 13, $M_{x}$ is calculated as:

$$
M_{x}=M-\frac{q x^{2}}{2}-P x+\frac{N w x}{L}
$$

Therefore, Eq. (28) is developed as shown next: 


$$
\Delta_{b}=M Y_{1}+N Y_{2}-q Y_{3}-P Y_{4}
$$

Where:

$$
Y_{1}=\frac{L_{s} Z}{E I} ; \quad Y_{2}=\frac{w L_{s}^{2} Z}{2 E I L} ; \quad Y_{3}=\frac{L_{s}^{3} Z}{6 E I} ; \quad Y_{4}=\frac{L_{s}^{2} Z}{2 E I}
$$

The length of the sagging moment region $\left(L_{s}\right)$ may be approximately taken as $L / 2$ or calculated precisely during the analysis.

Therefore, the total axial deformation is expressed in terms of $M^{\prime}, M, N, w, q$ and $P$ by incorporating the expressions for $u^{\prime}, u, \Delta^{\mathrm{a}}$ and $\Delta_{b}$-i.e. Eqs. (3), (4), (27) and (30) respectively - into Eq. (26).

\subsection{Beam gravity loading}

By substituting $M^{\prime}, M$ and $N$ from Eqs. (22), (23) and (25) respectively into the final expression for the total axial deformation defined in section 4.3, an equation linking the beam gravity loading $(q$ and $P$ ) with the beam deflection $(w)$ is obtained. The resulting equation may be developed in two ways:

- By solving the equation with respect to $q$, the following $q$ - $w$ relationship is obtained:

$$
q=\frac{\omega_{1}-\omega_{3} P}{\omega_{2}}
$$

- $\quad$ By solving the equation with respect to $P$, the following $P-w$ relationship is obtained:

$$
P=\frac{\omega_{1}-\omega_{2} q}{\omega_{3}}
$$

Where:

$$
\begin{aligned}
& \omega_{1}=\frac{w^{2}}{2 L}+\frac{\lambda_{3} \xi}{\kappa_{3}}-\alpha_{2}{ }^{\prime} \lambda^{\prime}-\alpha_{2} \lambda+\gamma_{2}{ }^{\prime}+\gamma_{2}-\lambda Y_{1} \\
& \omega_{2}=-\frac{\mu_{3} \xi}{\kappa_{3}}+\frac{\xi L^{2}}{2 \kappa_{3}}+\alpha_{2}{ }^{\prime} \mu^{\prime}+\alpha_{2} \mu+\mu Y_{1}-Y_{3} \\
& \omega_{3}=-\frac{v_{3} \xi}{\kappa_{3}}+\frac{\xi L}{\kappa_{3}}+\alpha_{2}{ }^{\prime} v^{\prime}+\alpha_{2} v+v Y_{1}-Y_{4} \\
& \xi=\alpha_{2}{ }^{\prime} \kappa^{\prime}+\alpha_{2} \kappa+z^{\prime} \beta_{2}{ }^{\prime}+z \beta_{2}+\frac{1}{K^{\mathrm{a}}}+\kappa Y_{1}+Y_{2}
\end{aligned}
$$


Each of the above load-deflection relationships applies to a different scheme of gravity loading. In particular, Eq. (31) links the beam deflection $(w)$ with a uniformly distributed loading $(q)$ applied to the beam. However, it may also consider the effects of a constant point load $(P)$ applied to the mid-span of the double-span beam. Clearly, in the absence of mid-span point load (i.e. $P=0$ ), Eq. (31) is simplified accordingly. Similarly, Eq. (32) links the beam deflection with a point load $(P)$ applied to the mid-span of the double-span beam, while it may also account for the presence of a constant uniformly distributed load $(q)$.

\subsection{Concluding remarks}

The set of the equations obtained in sections 4.1-4.4 forms an analytical method for describing the complete static behaviour of axially restrained beams following column removal. The nonlinear load-deflection response can be accurately traced in a step-by-step fashion - i.e. using the spreadsheet approach - by gradually increasing the beam deflection and assessing the corresponding level of gravity loading using Eq. (31) or Eq. (32). Apart from the load-deflection response, the beam axial load and the connection bending moments may be assessed in each step of the analysis using Eqs. (25), (22) and (23) respectively. In addition, the connection deformations can be defined using Eqs. (1)-(4), thereby making it possible to make direct comparisons with the corresponding deformation limits in each step and thus determine the ultimate capacity of the system. Therefore, a detailed representation of the full range of the response up to failure is developed.

Although the method has been based on axially restrained composite beams, it is also applicable to axially restrained bare steel beams as well as composite or bare steel beams with different boundary conditions. Those cases may be covered by applying minor simplifications as described next:

- When the beam comprises only a bare steel section, a uniform stiffness should be considered (i.e. equal stiffness in both the hogging and sagging moment regions). Connection behaviour may still be modelled based on the mechanical approach described in section 3, by employing suitable connection spring models. More information is provided in the corresponding publication [20].

- The behaviour of axially unrestrained beams may be modelled by considering an infinitesimal value for the stiffness of the axial support $\left(K_{s}\right)$. In the absence of axial restraint, no axial load should be generated in the beams and therefore performance should be governed only by flexural effects. Beams may be considered as axially unrestrained when the degree of axial restraint provided by the 
surrounding structure is relatively low, e.g. when the beam is located adjacent to the edge of the frame.

- The behaviour of cantilever beams may be approximated by considering infinitesimal values for both the stiffness of the axial support $\left(K_{s}\right)$ and the rotational stiffness of the mid-span connection $\left(S_{j}\right)$. Some beams may be regarded as cantilevers when, apart from the absence of axial restraint, the degree of rotational restraint provided by one of the supporting members is relatively low. A representative example is shown in Fig. 1(d) where the primary beam is modelled as cantilever.

The proposed method comprises in-plane analyses of the beam behaviour following column removal. In effect, progressive collapse triggered by the loss of a load bearing member is likely to be a 3-dimensional problem. Owing to the inherent simplifications, the proposed method is incapable of addressing 3dimensional effects such as changes in the effective width or membrane action likely to be generated in the slab, which may only be simulated by detailed finite element analyses [15, 31, 32]. Although the importance of such effects should be appropriately appraised, the proper use of simpler analysis tools similar to the analytical method proposed herein offers several advantages over complex and timeconsuming detailed analyses as discussed in section 1 .

\section{Verification study \\ 5.1. Layout of the study}

The analytical method developed in section 4 is verified herein against detailed numerical models using the nonlinear structural analysis program ADAPTIC [33]. Consideration is given to the substructure shown in Fig. 14 which consists of four identical beams carrying a uniformly distributed gravity loading $(q)$ and supported by UC $305 \times 305 \times 118$ steel columns, with the beam longitudinal axes being perpendicular to the major axes of the column cross-sections. Two different types of structure are considered including bare steel and composite. The bare steel structure comprises only UB406 $\times 140 \times 39$ steel beam sections (i.e. the composite slab shown in Fig. 14 is excluded) while the composite structure comprises the same steel beam sections acting compositely with a composite slab. The slab consists of reinforced concrete C30/37 cast on a trapezoidal steel decking. The height of the steel decking is $60 \mathrm{~mm}$ and the total depth of the slab is 130 $\mathrm{mm}$. Full shear connection between the steel beam sections and the composite slab is considered and the width of the slab is determined based on the effective breadth approach of EC4 [30]. 
As shown in Fig. 15(a), the beam-to-column joints of the bare steel structure consist of flush endplate 1 connections with four rows of bolts. The same bare steel connection arrangements are used as part of the composite joints employed in the composite structure as shown in Fig. 15(b), where the slab is intended to contribute to the behaviour. The material properties of the various steel components are given in Fig. 15.

The study involves notional removal of the central column as depicted in Fig. 14. Following column removal, the two internal beams will form a double-span beam mechanism while the two adjacent beams on either side will provide a degree of axial restraint to the system. Various alternative arrangements are considered for each structure including different combinations of beam span lengths $(L)$, connection endplate thicknesses $\left(t_{p}\right)$ and amounts of connection reinforcement. In particular, the following combinations are applied:

a) Bare steel structure with $L=6 \mathrm{~m}$ and various connection endplate thicknesses (i.e. $t_{p}=8,10,12$ and $14 \mathrm{~mm})$.

b) Bare steel structure with $t_{p}=10 \mathrm{~mm}$ and various beam span lengths (i.e. $L=4,6,8$ and $10 \mathrm{~m}$ ).

c) Composite structure with $t_{p}=10 \mathrm{~mm}, L=6 \mathrm{~m}$ and various amounts of connection reinforcement (i.e. 2, 4, 6 and 8 reinforcement bars)

d) Composite structure with $t_{p}=10 \mathrm{~mm}, 4 \Phi 16$ connection reinforcement and various beam span lengths (i.e. $L=4,6,8$ and $10 \mathrm{~m}$ ).

\subsection{Modelling of connection behaviour}

For the set of the above structural arrangements, the mechanical properties of the connection components are determined based on the component method of EC3 [29] and EC4 [30]. Each bolt-row consists of several basic components acting in series, i.e. endplate in bending, bolts in tension and beam web in tension - the columns are considered as rigid and therefore no consideration is given to the contribution of the column web in bending. The effective design resistance and elastic stiffness of each bolt-row, as defined based on the corresponding properties of the constitutive components, are given in Table 1. In this study, the post-limit stiffness of each bolt-row is defined based on the corresponding effective elastic stiffness by considering 1\% strain-hardening. The mechanical properties of the connection reinforcement are presented in Table 2. Similarly to the bolt-rows, the post-limit stiffness is modelled based on the corresponding elastic stiffness by considering $1 \%$ strain-hardening.

Modelling of the compression zone of the bare steel connections and the support connections of the composite structure should account only for the behaviour of the beam flange/web in compression which is 
approximated as rigid-perfectly plastic with a design resistance of $660.0 \mathrm{kN}$. On the other hand, the 1 compression zone of the mid-span composite connection comprises the concrete slab which is under compression. For simplicity, a constant centre of compression at the mid-thickness of the solid section of the slab is considered in this study - however, a rather more detailed approach that accounts for the actual depth of the slab in compression based on the distribution of the stresses may be adopted [20].

Connection failure is defined as the failure of a single connection component in the tension zone. Most likely, failure of a bare steel endplate connection is governed by the deformation capacity of the most remote bolt-row with respect to the centre of compression. Therefore, the top (i.e. Br 1) and the bottom (i.e. $\mathrm{Br} 4$ ) bolt-rows are regarded as the most critical components of the support and mid-span connections respectively. In this study, the bolt-row deformation capacity is considered as equal to 100 times the yield deformation on the presumption that the force in the bolt-row does not exceed the tensile resistance of the bolts. Otherwise, the deformation capacity is determined from the bolt-row force-deformation characteristic with respect to the resistance of the bolts. The limits presented in Table 3 are based on the above criteria, where it is shown that the deformation capacity is limited by failure of the bolts when the endplate thickness is 12 or $14 \mathrm{~mm}$.

In the composite structure, failure of the support connections may be governed by fracture of the reinforcement. Deformation limits are determined based on the model proposed by Anderson et al. [34], by considering $10 \%$ ultimate strain for the bare reinforcement. For $6 \mathrm{~m}$ beam span, the limits are given in Table 2. For $4 \mathrm{~m}, 8 \mathrm{~m}$ and $10 \mathrm{~m}$ beam span lengths, the deformation capacities of $4 \Phi 16$ connection reinforcement are defined as $13.5 \mathrm{~mm}, 11.0 \mathrm{~mm}$ and $7.0 \mathrm{~mm}$ respectively.

\subsection{Modelling of axial restraint}

The degree of axial restraint depends on the axial stiffness provided by the neighbouring structure on either side of the double-span beam mechanism. In this study, an axial restraint is imposed by the adjacent beams and connections as depicted in Fig. 14. Since the behaviour of both components is considered as linear elastic, the axial support may be modelled based on the corresponding effective elastic stiffness (i.e. $K_{s}$ ). The axial stiffness of the beam-to-column connections is different when subject to tension or compression. Therefore, different values are obtained for the compressive and tensile stiffness of the axial support for each arrangement as shown in Table 4.

\subsection{ADAPTIC modelling}


The models employed in the ADAPTIC [33] numerical analyses are presented in Fig. 16. Due to symmetry, only half of the double-span beam system is considered. The steel beams and the concrete flange are modelled by cubic elasto-plastic 2D beam-column elements that allow for material and geometric nonlinearity. Composite action and full shear connection between the two components is effected through a series of rigid links. The spring models shown in Fig. 15 are employed for simulating the responses of the connections. The rigid links included in the spring models are modelled by $2 \mathrm{D}$ contact elements while the various connection components are modelled by $2 \mathrm{D}$ elasto-plastic elements based on the mechanical properties defined in section 5.2. The axial restraint is approximated by a linear elastic boundary spring using the effective stiffness values obtained in section 5.3.

\subsection{Analyses and results}

Full descriptions of the behaviour of the different arrangements following column removal have been obtained by numerical nonlinear static analyses using ADAPTIC and analytical applications using the proposed method. The analytical load-deflection curves have been determined using the $q$ - $w$ relationship of Eq. (31), by setting $P=0$ (i.e. no point gravity load is applied to the mid-span of the double-span beam). Starting from the unloaded condition, a step-by-step analysis was conducted for each case using the Excel spreadsheet software, where the beam deflection was increased by $1 \mathrm{~mm}$ and the corresponding gravity loading was assessed at each step of the analysis. The resulting curves are compared with the corresponding ADAPTIC predictions in Fig. 17 where it is confirmed that agreement between the two methods of analysis is excellent.

Failure points due to reaching the specified connection deformation limits are also predicted with excellent accuracy as shown in Fig. 17. For each bare steel arrangement, the deformation capacity of the support connection is defined as critical. On the other hand, collapse resistance of the composite arrangements is defined based on the limit deformation of the bottom bolt-row of the mid-span connection apart from the 10 $\mathrm{m}$ beam span case where resistance is governed by failure of the support connection due to rebar fracture. Performance after the specified failure points is only of academic interest.

In some cases, minor discrepancies are observed at very large deflections and typically well beyond failure. The analytical method is based on the assumption that the behaviour of the beam section is linear elastic, whereas the advanced numerical analyses may account for nonlinear effects due to yielding and/or local buckling. Although such effects are intended to be described by the connection behaviour, yielding of the 
beam web - most likely in the vicinity of the connections - due to the substantial tensile forces developed

at large deflections may indeed result in decreases in the stiffness of the system.

An important feature of the proposed analytical method is that it is not limited only to the prediction of the load-deflection response but it can provide a complete description of performance including representations of the behaviour of the various constitutive components. Using Eqs. (22), (23) and (25), the connection bending moments $\left(M^{\prime}\right.$ and $\left.M\right)$ and the beam axial load $(N)$ have been determined at each step of the analysis and they are plotted against the beam deflections in Fig. 18. Again, agreement between the results of the two methods of analysis is excellent and it is therefore established that the analytical method may address in detail every aspect of performance.

Although both methods of analysis are based on similar modelling simplifications (i.e. they are both inplane analyses and thus incapable for addressing 3D effects), the potential of describing the complete behaviour of axially restrained beams using only spreadsheet calculations instead of sophisticated finite element software is a promising advance in studying the mechanics of the problem. Provided the various formulae are suitably incorporated into a spreadsheet program, the proposed method may easily be applied for rapid examinations of different alternatives. The interplay between the behaviour of the various components and the influence of each individual component on overall performance can be assessed directly by comparing the corresponding results. This is facilitated considerably by the faculty of illustrating graphically the complete set of the results as shown in Figs. 17 and 18. Therefore, important aspects of the behaviour such as the effects of the beam axial load on the connection response, the physical reasons behind the compressive arching and tensile catenary actions and the connection deformation modes likely to govern performance can be comprehensively explored.

\section{Validation against experimental results}

The proposed analytical method has also been validated against the results of an experimental study performed at the University of Liège as part of the collaborative research project on structural robustness reported in [11]. The study adopted the concept of column removal to examine the behaviour of a composite frame building designed according to the provisions of EC4. A substructure was isolated from the frame and tested as shown in Fig. 19(a). It comprises a symmetric double-span composite beam with a missing column in the middle and an adjacent system on each side representing the axial restraint provided by the neighbouring structure. Details of the beam-to-column joints are presented in Fig. 20. The same joint configurations were also tested in isolation against combined loading at the University of Stuttgart [11]. 
The mechanical approach for modelling connection behaviour derived by Stylianidis and Nethercot [20] was validated against the results of the joint tests performed at the University of Stuttgart. In that validation study, the mechanical properties of the various components have been defined based on the actual material properties given in [11]. The properties of the tensile components are given in Table 5. The compression zone of the support connection which is subject to hogging moment after column loss comprises the beam flange/web and the column web in compression. The behaviour of those components has been approximated by a bi-linear characteristic defined by $290.2 \mathrm{kN}$ design resistance, $1283.8 \mathrm{kN} / \mathrm{mm}$ effective elastic stiffness and $13.0 \mathrm{kN} / \mathrm{mm}$ post-limit stiffness. The centre of compression of the mid-span connections which are subject to sagging moments after column loss was assumed at the mid-thickness of the concrete slab section in compression based on the rectangular stress distribution assumption. More details about the connection modelling may be found in the corresponding publication [20].

As shown in Fig. 19(a), two horizontal jacks calibrated so as to exhibit a tensile stiffness of $3.278 \mathrm{kN} / \mathrm{mm}$ on each side of the substructure were employed. As described in Fig. 19(b) however, additional axial restraint is provided by the adjacent frames owing to the rotational stiffness possessed by the adjacent connections of the support joints. The rotational stiffness of each adjacent connection $\left(S^{\prime \prime}{ }_{j}\right)$ is approximated as $3046.7 \mathrm{kNm}$ based on the elastic stiffness of the bolt-rows and the post-limit stiffness of the reinforcement bars - i.e. it is assumed that when the axial restraints are actually activated, the design resistance of the reinforcement bars has already been exhausted owing to excessive rotation of the support connection on the other side of the support joint. Therefore, the adjacent frame provides an axial stiffness $\left(K_{j}\right)$ of $2.74 \mathrm{kN} / \mathrm{mm}$ which is obtained based on the rotational stiffness of the adjacent connection as described in Fig. 19(b). The sum of the axial stiffness provided by the horizontal jack and the axial stiffness provided by the adjacent frame yields a total axial stiffness $\left(K_{s}\right)$ of $6.02 \mathrm{kN} / \mathrm{mm}$.

The test involved progressive application of a vertical load to the mid-span of the double-span beam system through a vertical jack, as shown in Fig. 19(a), until collapse of the specimen. The analytical method developed in section 4 has been used for simulating performance by considering half of the symmetric double-span beam system as shown in Fig. 19(c). For describing the load-deflection curve, Eq. (32) which links the mid-span deflection with a point load applied to the mid-span of the system has been employed. The analytical prediction is shown in Fig. 21 where it is confirmed that it closely resembles the corresponding test curve. 
In the test, the reinforcement in the vicinity of the support connection fractured at approximately $615 \mathrm{~mm}$

mid-span deflection. Although the system was still able to support some additional load applied by the vertical jack until collapse, the stiffness reduced considerably after the reinforcement loss as shown in Fig. 21. The proposed analytical method does not account for the effects of progressive failure of the various connection components but essentially considers that failure of the most critical connection component triggers collapse of the system. Therefore, comparison should be limited only to the behaviour up to failure of the connection reinforcement. This includes the elastic phase, a plastic phase governed by flexural effects where some gradual gain in resistance due to strain-hardening is observed and the tensile stage where performance is enhanced by the tensile axial load developed in the beams. The analytical prediction represents the behaviour in each of those phases with great accuracy.

In the relevant validation study reported in [20], which involved analytical representations of the joint behaviour, it was determined that the deformation capacity of the connection reinforcement for the given joint configuration is approximately $10 \mathrm{~mm}$. Based on this deformation limit, it has been possible to obtain an explicit prediction of 'failure' of the substructure - i.e. denoting, in effect, a distinct reduction of its capability for supporting additional loading - due to reinforcement rupture in the vicinity of the support connection. The 'failure' point defined based on the analytical process is in good agreement with the corresponding experimental prediction as shown in Fig. 21.

Overall, agreement between the analytical predictions and the test results may be regarded as excellent in the sense that the analytical method relies on some deliberate simplifications and assumptions. One such simplification is associated with the representation of the behaviour of the connection components. Although the simplified bi-linear approximations have been deemed to be effective in describing the basic features of performance [20], more sophisticated simulations - i.e. using tri-linear or multi-linear characteristics - may provide more detailed representations. The mechanical approach for modelling connection behaviour derived in [20] is sufficiently general to allow various techniques for component characterisation. Therefore, it offers the possibility of incorporating whatever degree of sophistication is considered appropriate. In this regard, the connection characteristics may also be developed so as to incorporate explicit representations of failure, thus allowing for modelling the effects of progressive failure of the constitutive components on the beam response.

\section{Conclusions}


Methods for assessing the susceptibility of building structures to progressive collapse need to become more

similar to conventional structural design in terms of understanding structural behaviour, employing suitable modelling approaches and implementing quantitative comparisons between alternative arrangements rather than relying on prescriptive rules. A continuing research programme at Imperial College London aims at providing such a facility through the development of a complete design framework. The present paper presents part of the work conducted on simplifying the analysis required to describe the behaviour of building structures following column removal.

An explicit analytical method for modelling the nonlinear static response of axially restrained steel and composite beams following column removal is developed. A detailed description of the derivation process including definition of all the necessary assumptions and simplifications is provided. The procedure is based on the slope-deflection approach which is developed in a way that suitable representations of the connection behaviour during progressive collapse are incorporated into the analysis.

The proposed analytical method comprises a set of explicit formulae that link the imposed beam deflection with the beam gravity loading and the various component forces and deformations - such as connection bending moments, beam axial load and connection rotations - developed during the different stages of the response. Behaviour can be actually traced through an incremental step-by-step analysis using the spreadsheet method, thus allowing for detailed representations of the full range of the response up to failure to be derived.

Verification studies are conducted based on results obtained from rigorous numerical analyses using ADAPTIC and available tests, where excellent agreement is obtained in all cases. The results confirm that the proposed method is capable of describing explicitly the rather complex behaviour of axially restrained beams. It is shown that the basic features of the response such as material and geometric nonlinearity are modelled sufficiently, thereby the dominant mechanisms that govern performance such as compressive arching and tensile catenary actions are effectively taken into account.

This new development forms an effective and efficient analysis procedure that contrasts in its simplicity of application with detailed numerical methods. It offers the capability of conducting comprehensive parametric studies by examining different alternatives, which is an essential component for studying in detail the mechanics of the behaviour. In addition, it provides quantitative representations of the behaviour of each constitutive component and thereby assists with understanding the effects of the various structural parameters on overall performance. Therefore, the proposed analytical method represents a promising 
advance in modelling, studying and understanding the structural behaviour of steel and composite

structures during progressive collapse.

\section{References}

[1] Office of the Deputy Prime Minister (2004), The Building Regulations 2000, Part A, Schedule 1: A3, Disproportionate Collapse, London, UK.

[2] EN 1991-1-7 (2006), Eurocode 1: Actions on Structures - Part 1-7: General Actions - Accidental Actions, Brussels.

[3] GSA (2003), Progressive Collapse Analysis and Design Guidelines for New Federal Office Buildings and Major Modernization Projects, General Services Administration, USA.

[4] DoD (2013), Unified Facilities Criteria (UFC): Design of Buildings to Resist Progressive Collapse, Unified Facilities Criteria (UFC) 4-023-03, Department of Defense, USA.

[5] Arup (2011), Review of International Research on Structural Robustness and Disproportionate Collapse, On behalf of DCLG and CPNI, London.

[6] Liu, R., Davison, B., and Tyas, A. (2005), A study of progressive collapse in multi-storey steel frames, ASCE Structures Congress 2005, New York, pp. 1-9.

[7] Byfield, M.P., and Paramasivam, S. (2007), Catenary action in steel-framed buildings, ICE Proceedings, Structure \& Buildings, Vol. 160 (SB5), pp. 247-257.

[8] Vlassis, A.G., Izzuddin, B.A., Elghazouli, A.Y., and Nethercot, D.A. (2008), Progressive collapse of multi-storey buildings due to sudden column loss - Part II: Application, Engineering Structures, Vol. 30, pp. 1424-1438.

[9] Nethercot, D.A., Stylianidis, P., Izzuddin, B.A., and Elghazouli, A.Y. (2010), Resisting progressive collapse by the use of tying resistance, Steel and Composite Structures, ed. Uy B. et al., Research Publishing, pp. 94-109.

[10] Nethercot, D.A., and Stylianidis, P. (2011), Utilising catenary action as a method for resisting progressive collapse, Advances in Steel and Aluminium Structures, ed. Lau Hieng Ho., Research Publishing, pp. 22-28.

[11] Kuhlmann, U., Rölle, L., Jaspart, J.-P., Demonceau, J.-F., Vassart, O., Weynand, K., et al. (2009), Robust Structures by Joint Ductility, Final Report EUR 23611, Luxemburg.

[12] Sadek, F., Main, J.A., Lew, H.S., Robert, S.D., Chiarito, V.P., and El-Tawil, S. (2010), An Experimental and Computational Study of Steel Moment Connections under a Column Removal Scenario, NIST Technical Note 1669, National Institute of Standards and Technology, Gaithersburg, MD. 
[13] Fu, F. (2009), Progressive collapse analysis of high-rise buildings with 3-D finite element modelling method, Journal of Constructional Steel Research, Vol. 65, pp. 1269-1278.

[14] Sadek, F., Main, J.A., Lew, H.S. and Bao, Y. (2011), Testing and analysis of steel and concrete beam-column assemblies under a column removal scenario, Journal of Structural Engineering, Vol. 137 (9), pp. 881-892.

[15] Li, H.,and El-Tawil, S. (2014), Three-dimensional effects and collapse resistance mechanisms in steel frame buildings, Journal of Structural Engineering, Vol. 140 (8).

[16] Marjanishvili, S.M. (2004), Progressive analysis procedure for progressive collapse, Journal of Performance of Constructed Facilities, Vol. 18 (2), pp. 79-85.

[17] Marjanishvili, S., and Agnew, E. (2006), Comparison of various procedures for progressive collapse analysis, Journal of Performance of Constructed Facilities, Vol. 20 (4), pp. 365-374.

[18] Kim, J., and Kim, T. (2009), Assessment of progressive collapse-resisting capacity of steel moment frames, Journal of Constructional Steel Research, Vol. 65, pp. 169-179.

[19] Izzuddin, B.A., Vlassis, A.G., Elghazouli, A.Y., and Nethercot, D.A. (2008), Progressive collapse of multi-storey buildings due to sudden column loss - Part I: Simplified assessment framework, Engineering Structures, Vol. 30, pp. 1308-1318.

[20] Stylianidis, P.M., and Nethercot, D.A. (2015), Modelling of connection behaviour for progressive collapse analysis, Journal of Constructional Steel Research (under review).

[21] Khandelwal, K., El-Tawil, S., Kunnath, S.K., and Lew, H.S. (2008), Macromodel-based simulation of progressive collapse: Steel frame structures, Journal of Structural Engineering, ASCE, Vol. 134 (7), pp. 1070-1078.

[22] Kim, T., Kim, J., and Park, J. (2009), Investigation of progressive collapse-resisting capability of steel moment frames using push-down analysis, Journal of Performance of Constructed Facilities, ASCE, Vol. 23 (5), pp. 327-335.

[23] Yang, B., and Tan, K.H. (2012), Numerical analyses of steel beam-column joints subjected to catenary action, Journal of Constructional Steel Research, Vol. 70, pp. 1-11.

[24] Guo, L., Gao, S., Fu, F., and Wang, Y. (2013), Experimental study and numerical analysis of progressive collapse resistance of composite frames, Journal of Constructional Steel Research, Vol. 89, pp. 236-251.

[25] Yang, B., and Tan, K.H. (2014), Behaviour of composite beam-column joints in a middle-columnremoval scenario: Experimental tests, Journal of Structural Engineering, ASCE, Vol. 140 (2).

[26] Li, L., Wang, W., Chen, Y., and Lu, Y. (2015), Effect of beam bolt arrangement on catenary behaviour of moment connections, Journal of Constructional Steel Research, Vol. 104, pp. 22-36. 
[27] Stylianidis, P. (2011), Progressive Collapse Response of Steel and Composite Buildings, PhD Thesis, Department of Civil and Environmental Engineering, Imperial College London, UK.

[28] Del Savio, A.A., Nethercot, D.A., Vellasco, P.C.G.S., Andrade, S.A.L., and Martha L.F. (2009), Generalised component-based model for beam-to-column connections including axial versus moment interaction, Journal of Constructional Steel Research, Vol. 65, pp. 1876-1895.

[29] EN 1993-1-8 (2005), Eurocode 3: Design of Steel Structures - Part 1.8: Design of Joints, Brussels.

[30] EN 1994-1-1 (2004), Eurocode 4: Design of Composite Steel and Concrete Structures - Part 1.1: General Rules and Rules for Buildings, Brussels.

[31] Alashker, Y., Li, H., and El-Tawil, S. (2011), Approximations in progressive collapse modelling, Journal of Structural Engineering, Vol. 137 (9), pp. 914-924.

[32] Zolghadr Jahromi, H., Vlassis, A.G., and Izzuddin, B.A. (2013) Modelling approaches for robustness assessment of multi-storey steel-composite buildings, Engineering Structures, Vol. 51, pp. 278-294.

[33] Izzuddin, B.A. (1991), Nonlinear Dynamic Analysis of Framed Structures, PhD Thesis, Department of Civil Engineering, Imperial College, University of London, UK.

[34] Anderson, D., Aribert, J.M., Bode, H., and Kronenburger, H.J. (2000), Design rotation capacity of composite joints, The Structural Engineer, Vol. 78 (6), pp. 25-19. 
List of Tables:

1 Table 1 Mechanical properties of connection bolt-rows.

4 Table 2 Mechanical properties of connection reinforcement.

Table 3 Deformation capacities of the most critical bolt-rows.

Table 4 Stiffness of axial support.

10

Table 5 Mechanical properties of the connection tensile components [20]. 
List of Figures:

Fig. 1. Sub-structural levels for progressive collapse assessment (based on Izzuddin et al. [19]).

Fig. 2. Simplified dynamic assessment and definition of pseudo-static response [19].

Fig. 3. Double-span beam condition created by column removal.

Fig. 4. Typical forms of beam and connection behaviour following column removal.

Fig. 5. Modelling of connection behaviour following column removal.

Fig. 6. Modelling of beam behaviour following column loss.

Fig. 7. Modelling of composite beams with non-uniform stiffness.

Fig. 8. Nodal forces of the clamped structure.

Fig. 9. Displacement modes of the released structure.

Fig. 10. Equilibrium of the system.

Fig. 11. Approximation of second-order geometric effects.

Fig. 12. Beam flexural deformation along different reference lines.

Fig. 13. Assessment of sagging bending moment.

Fig. 14. Layout of the structure.

Fig. 15. Connection layout and modelling.

Fig. 16. Finite element beam models.

Fig. 17. Beam nonlinear static responses.

Fig. 18. Component forces vs. beam deflections.

Fig. 19. Test layout [11] and modelling of the structure.

Fig. 20. Joint layout [11].

Fig. 21. Beam load-deflection predictions. 
Dimensions of Figures:

Fig. 1: 2-column fitting image

Fig. 2: 2-column fitting image

Fig. 3: 2-column fitting image

Fig. 4: 2-column fitting image

Fig. 5: 2-column fitting image

Fig. 6: 2-column fitting image

Fig. 7: Single-column fitting image

Fig. 8: Single-column fitting image

Fig. 9: Single-column fitting image

Fig. 10: Single-column fitting image

Fig. 11: Single-column fitting image

Fig. 12: Single-column fitting image

Fig. 13: Single-column fitting image

Fig. 14: 2-column fitting image

Fig. 15: 2-column fitting image

Fig. 16: Single-column fitting image

Fig. 17: 2-column fitting image

Fig. 18: 2-column fitting image

Fig. 19: 2-column fitting image

Fig. 20:.Single-column fitting image

Fig. 21:.Single-column fitting image 
Reviewer \#1:

1. The only concern is that verification with experimental results is limited to what is given Figure 21. This could, however, be compromised in view of the numerical comparison with an established computer software ADAPTIC.

Response:

Validation is not actually limited only to what is given in Fig. 21 because, as noted in the paper, the connection modelling approach has been validated in a previous publication (i.e. Reference 25) against relevant results of the experimental study of Reference 18. The analytical method of the present paper utilises the features of the connection modelling approach of Reference 25. Therefore, it is believed that the results of both validation studies i.e. the one presented in [25] and the one presented in section 6 of the present paper demonstrate sufficiently the validity of the proposed method.

2. Secondly, the title could be reworded as "Modelling of beam response for progressive collapse analysis of composite frames".

Response:

The suggestion of the Reviewer has been carefully appreciated but it has been decided to keep the original form of the title. The adopted methodology is general and may apply to all forms of structures, while only the detailed implementation is for composite frames. In addition, the proposed method is readily applicable for bare steel frames, with several bare steel arrangements having been employed in the verification study of section 5 .

\section{Reviewer \#2:}

1. Page 2 line 6: suggest that 'notable' or 'infamous' might be more appropriate than "remarkable".

Response:

'remarkable' has been substituted by 'notable'.

2. Page 2 line 43: References 6-8 are your own. Has no-one else published work that would support the assertion that the tie-force method has limitations? Inclusion of the work of others would further strengthen your case. 
Response:

Two new references (i.e. 5 and 6 in the revised manuscript), that strengthen the assertion and clarify that the limitations of the tie-force method are widely recognised, have been added. The associated text (page 2 lines 43-50) has been modified accordingly.

3. Page 3 line 2: Should not the statement "Much of the recent work conducted worldwide ...." be followed by a selection of references? (I am aware that these may be some of those referenced later for other purposes.)

Response:

A set of references (i.e. 6-15 in the revised manuscript) has been included.

4. Page 3 line 28: What does "more competitive" mean?

Response:

'more competitive' has been substituted by 'more representative'.

5. Page 4 line 2: Reference is made to Figure 2 and an energy-balance concept which is briefly explained in the next two sentences. Although this is considered in detail in another paper (ref 15), it might be useful to expand the explanation of this just a little more.

Response:

A more detailed explanation is provided in the revised manuscript, with the various definitions being in particular explained with respect to the associated figure (i.e. Fig. 2).

6. Page 4 line 43: "previously devised at Imperial College..." add reference.

Response:

Reference 20 has been added.

7. Page 4 line 58: understanding "of" the mechanics.

Response:

'of' has been added. 
8. Page 5 line 28 onwards: Fig 4 shows the load deflection response and notes that the response with and without axial restraint is shown. The subsequent description concentrates on the case with axial restraint but says little about what happens when such restraint is not provided. Although some readers may easily discern what the effect will be when there is no restraint it is perhaps worth explaining this e.g explaining why the dotted line goes through points $C$ and $D$ ?

Response:

The $2^{\text {nd }}$ and $3^{\text {rd }}$ paragraphs of section 2 have been divided into 4 paragraphs and developed so as to cover the Reviewer's suggestions. In particular, the basic features of the response in the absence of axial restraint are briefly described. In addition, it is explained why the dotted line goes through points $\mathrm{C}$ and D in Fig. 4 and it is quoted that further details may be found elsewhere (i.e. in reference 27).

9. Page 7 line 18: "performance of the connections" is a catch-all phrase. It would be helpful to state what performance characteristics are of crucial importance i.e. not only moment resistance but rotational ductility and axial resistance.

Response:

The following sentence has been added in response to the Reviewer's comment:

'Beam behaviour depends to a considerable extent on the ability of the connections to transmit the sorts of loading (i.e. bending moments and axial forces) generated following an initial damage whilst delivering the deformations needed to arrest collapse without exhausting their ductility limits.'

10. Page 8 line 14: drawing the reader's attention to the fact that the ' denotes the connection in hogging might be helpful (it can be seen from figure 5 but it does no harm to state it).

Response:

This is already illustrated in the next paragraph of the original manuscript (page 8 line 36). Since the original sentence may have not been stated properly however, it has been modified as follows:

'In the present paper, the addition of a note denotes that the quantity is associated with the hogging region (i.e. the region of the support connection).' 
11. Page 9 line 31: reference is made here to a linear elastic boundary spring. How is the value of this stiffness to be determined? Are there some suggested figures that users might adopt in the absence of a quite detailed analysis to determine the value?

Response:

The following text has been added:

'The stiffness of the boundary spring may approximately be assumed as the stiffness provided by the structural components in the immediate vicinity of the damaged structure - i.e. the axial stiffness of the beam and the connection on the opposite side of the support connections [8] and/or the flexural stiffness of the intact column sections that support the double-span beam [12]. Alternatively, it may be assessed based on the force-deformation ratio obtained from a linear elastic analysis of the neighbouring structure loaded by axial forces applied in the direction of the double-span beam [11].'

12. Page 10 line 26: What assumptions are made about the effective width and modular ratio when calculating the flexural stiffness?

Response:

The following text has been added at the end of the $1^{\text {st }}$ paragraph of section 4.1 :

'The width of the concrete flange may be determined based on the effective breadth approach of EC4 [30]. The nominal distance between zero bending moments may approximately be assumed as constant and determined according to the EC4 simplified approach by treating the double-span beam structure as a single-span beam supported at both ends. The uncracked section modulus can be determined based on the traditional transformed section method with transforming the effective breadth of the concrete flange to an equivalent breadth of steel.'

13. Page 16 line 33: the superscript should be "a" not alpha.

Response:

The superscript of notations $\Delta^{\mathrm{a}}$ and $K^{\mathrm{a}}$ has be corrected (both in Eqs. 26 and 27 and the associated text).

14. Page 25 line 14 onwards: The comparison of the method against ADPATIC is impressive but perhaps you should comment on the fact that the numerical method and the proposed simplified method are addressing the same idealised model of a real situation i.e they are in-plane analyses of what is likely to be a very 3-dimensional problem. Some 
consideration of the effect of the inherent simplifications (e.g. the use of a $2 \mathrm{D}$ model is incapable of addressing changes in effective width, or the membrane action likely to be generated in the slab) would give evidence of critical evaluation. Similarly, when comparing the method against test results, the finite width of the test specimen and the 2D nature of the test set up is ideally suited to show good correspondence with the proposed method. Some comments about this would demonstrate to the reader that you are aware of the likely effects of the simplification inherent in the proposed method.

Response:

The following paragraph has been included at the end of section 4.5 (references 31 and 32 had not been included in the original manuscript):

'The proposed method comprises in-plane analyses of the beam behaviour following column removal. In effect, progressive collapse triggered by the loss of a load bearing member is likely to be a 3-dimensional problem. Owing to the inherent simplifications, the proposed method is incapable of addressing 3-dimensional effects such as changes in the effective width or membrane action likely to be generated in the slab, which may only be simulated by detailed finite element analyses [15, 31, 32]. Although the importance of such effects should be appropriately appraised, the proper use of simpler analysis tools similar to the analytical method proposed herein offers several advantages over complex and time-consuming detailed analyses as discussed in section 1.'

In addition, the last paragraph of section 5 (i.e. page 25 line 14 of the original manuscript) has been developed as follows:

'Although both methods of analysis are based on similar modelling simplifications (i.e. they are both in-plane analyses and thus incapable for addressing 3D effects), the potential of...'

15. Page 29 line 45: I guess the degree of 'simplicity' is relative. Having read carefully the derivation of the method and how it might be implemented (including the use of EC3 and EC4 component-based modeling of the connections), it is considerably more involved than the use of prescriptive tying forces but much simpler than creating detailed FE models. The question of the value of the stiffness to be assumed for any surrounding structure is not really addressed - some guidance on suitable values to be adopted would be helpful.

Response:

The question of the value of stiffness provided by the surrounding structure is covered in the response to Comment 11. 


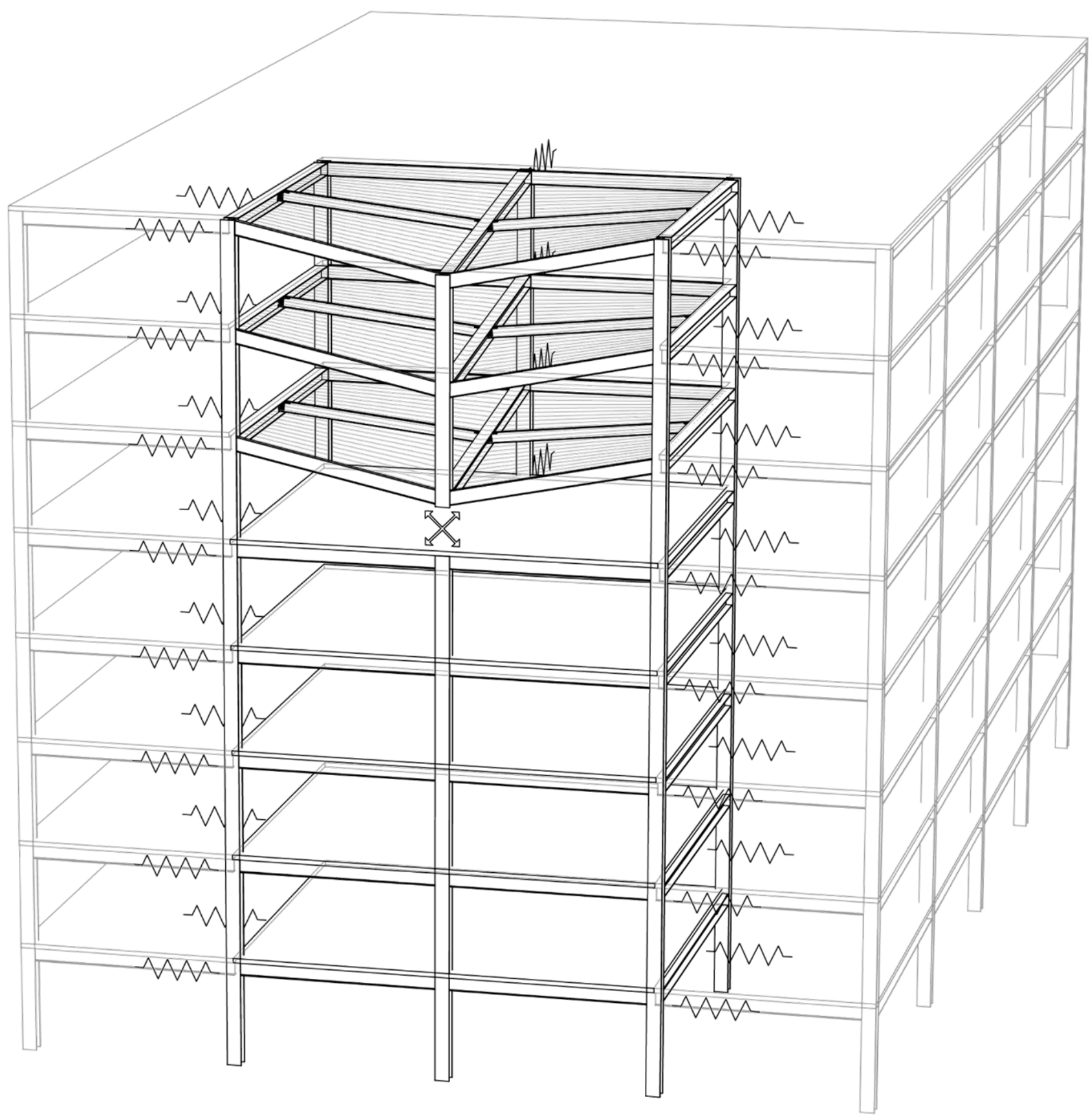

¿ Removed column
W Boundary spring

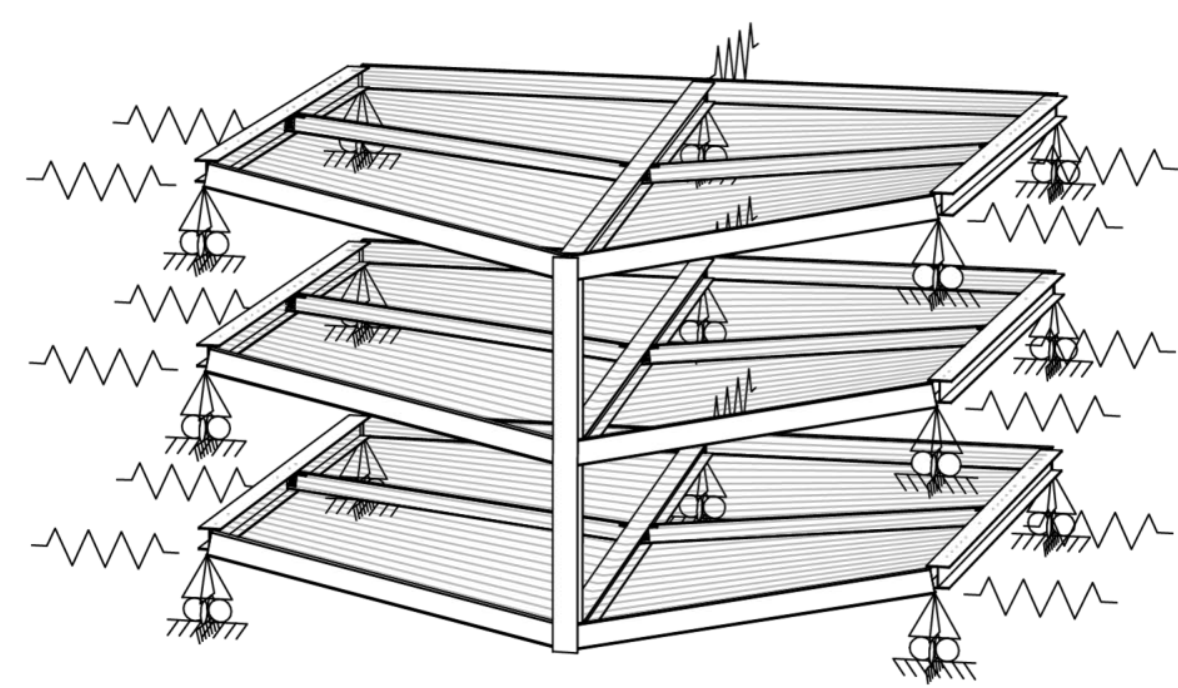

(b) Multiple-floor system

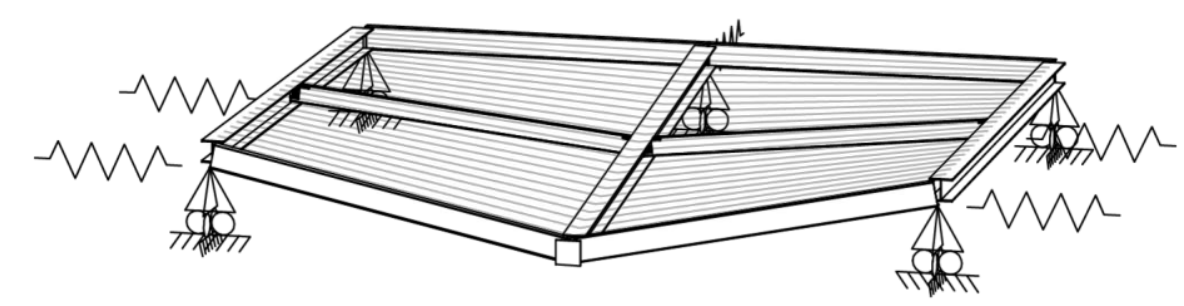

(c) Single-floor system

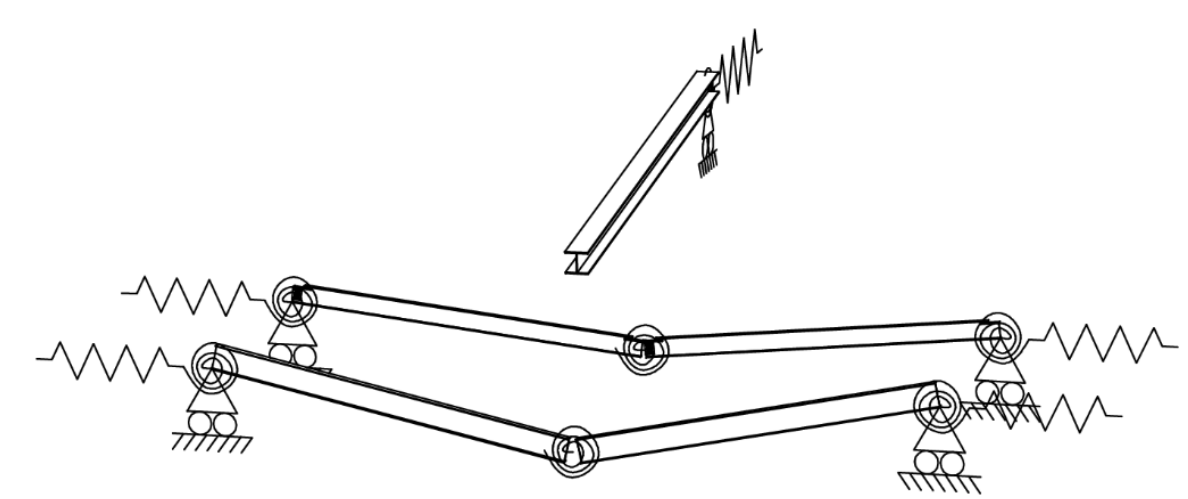

(d) Individual beam systems

(a) Full structure / affected structural bay 


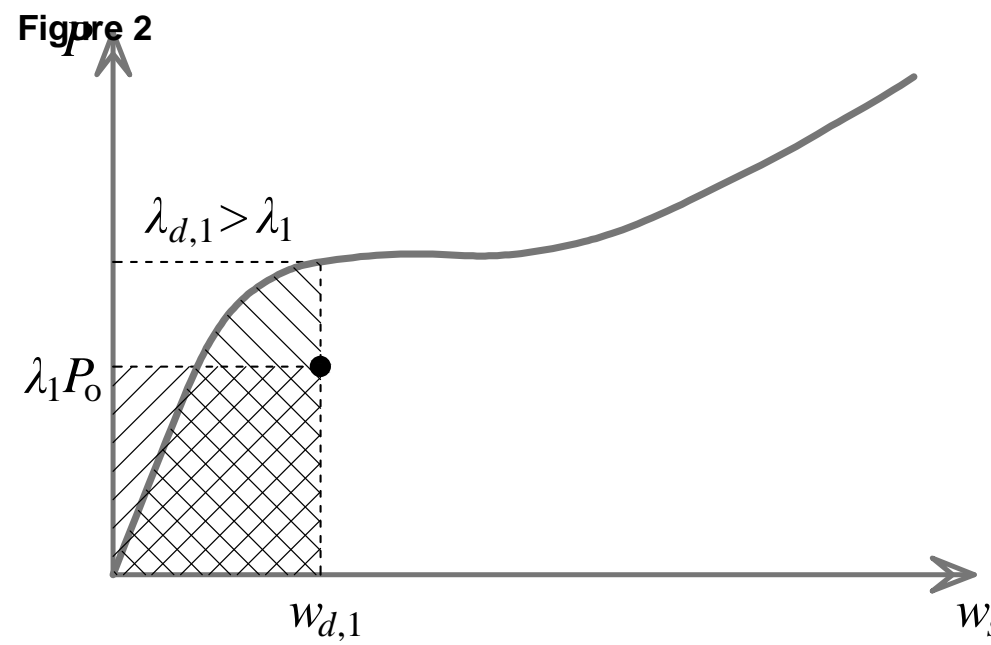

(a) Dynamic response $\left(P=\lambda_{1} P_{0}\right)$

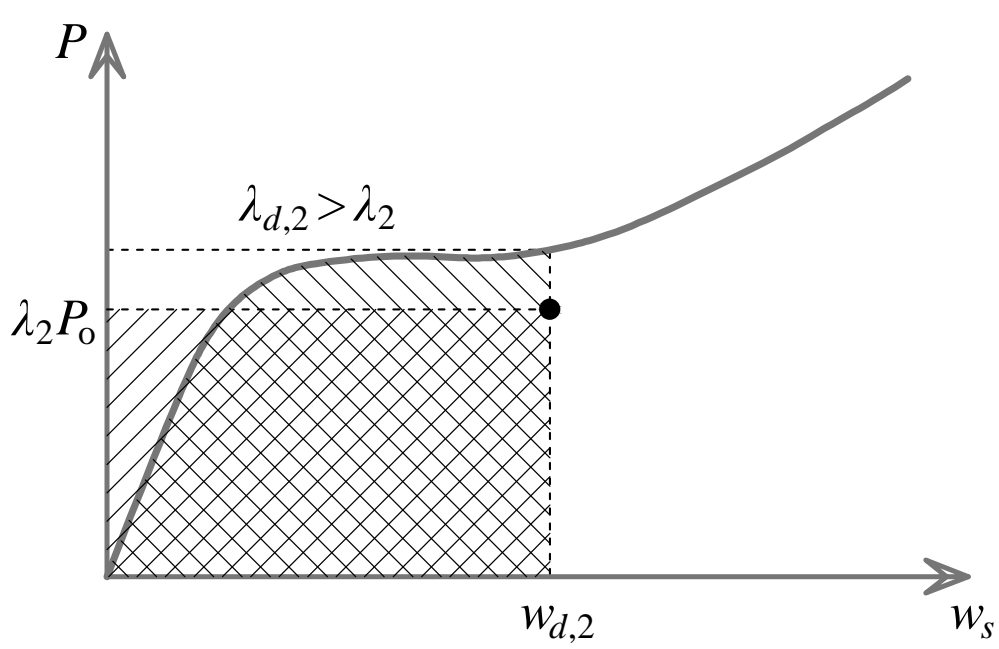

(b) Dynamic response $\left(P=\lambda_{2} P_{0}\right)$

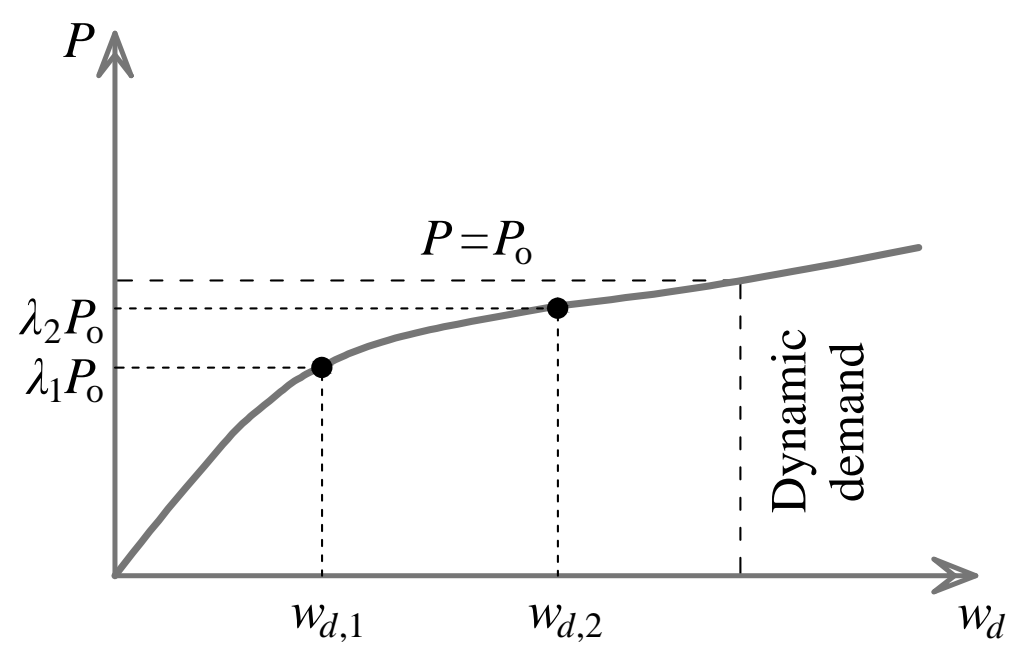

(c) Pseudo-static response 


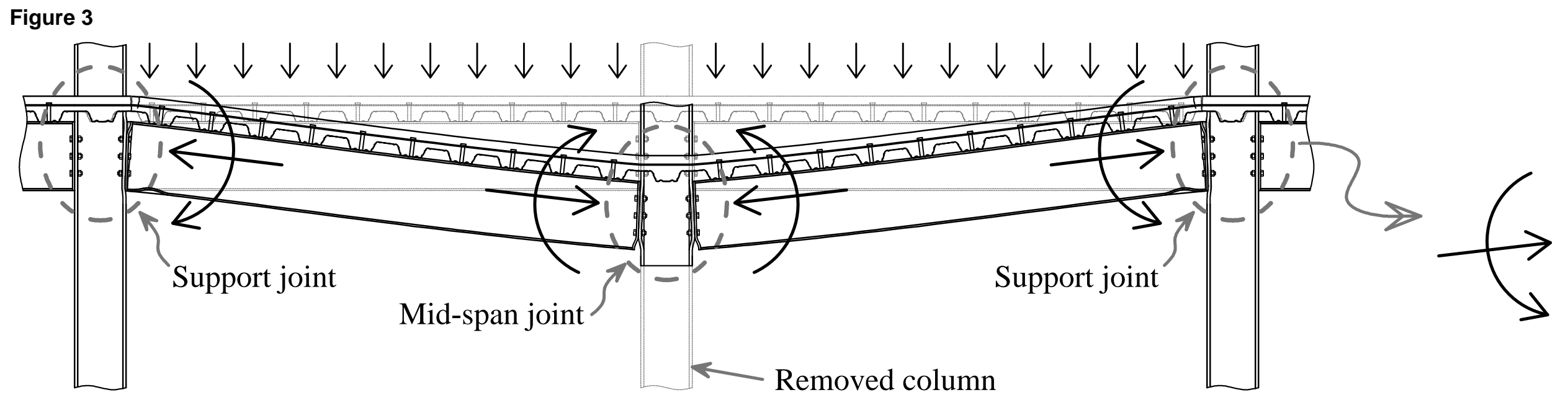

(a) Compressive arching stage

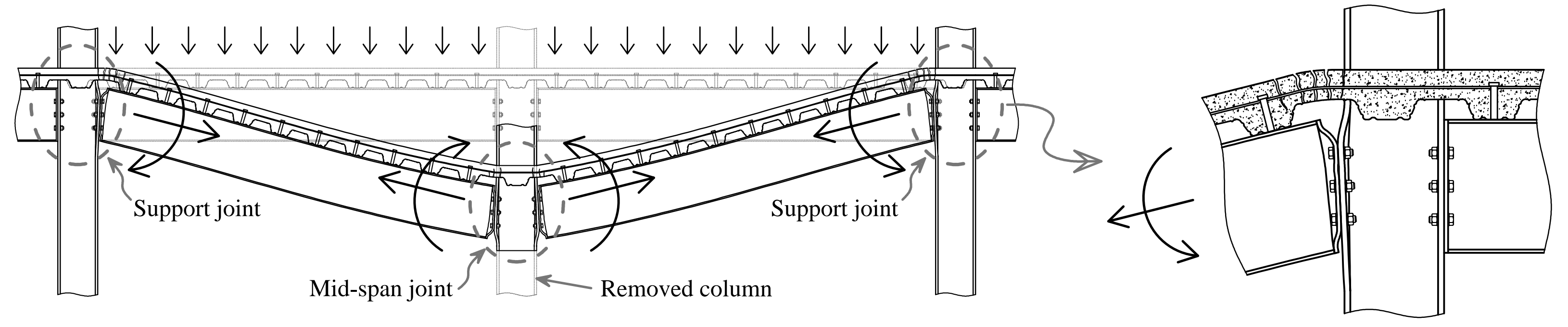

(b) Tensile catenary stage 

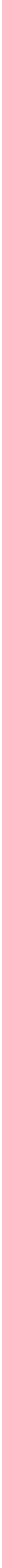

$E I$ : Beam flexural rigidity

$E A$ : Beam axial rigidity

$K_{s}$ : Support axial stiffness

$S_{j}^{\prime}$ : Support connection stiffness

$S_{j}$ : Mid-span connection stiffness

$L$ : Beam span

(c) Component forces and deformations

$q$ : Uniformly distributed load

$P$ : Mid-span point load

$M^{\prime}$ : Support connection bending moment

$M$ : Mid-span connection bending moment

$N$ : Beam axial load

$w:$ Beam deflection

$\varphi^{\prime}$ : Support connection rotation

$\varphi$ : Mid-span connection rotation

$\Delta_{s}:$ Support axial deformation 
Figure 7

犯以

$\downarrow \downarrow \downarrow \downarrow \downarrow \downarrow \downarrow \downarrow \downarrow \downarrow \downarrow \downarrow \downarrow \downarrow \downarrow \downarrow \downarrow$ EI',EA'

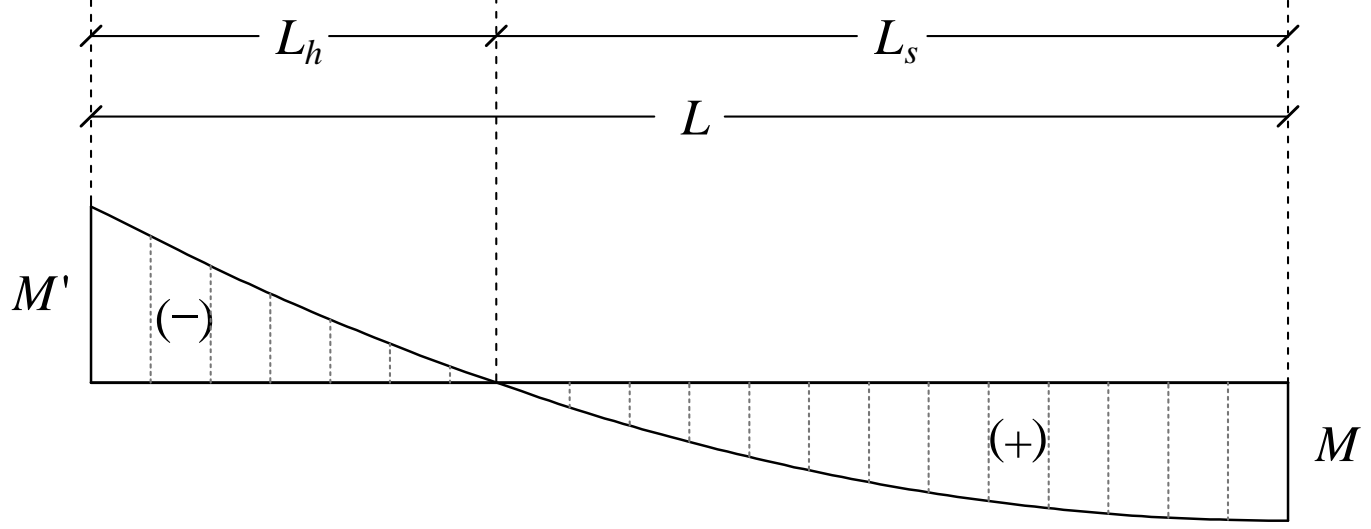


Figure 9
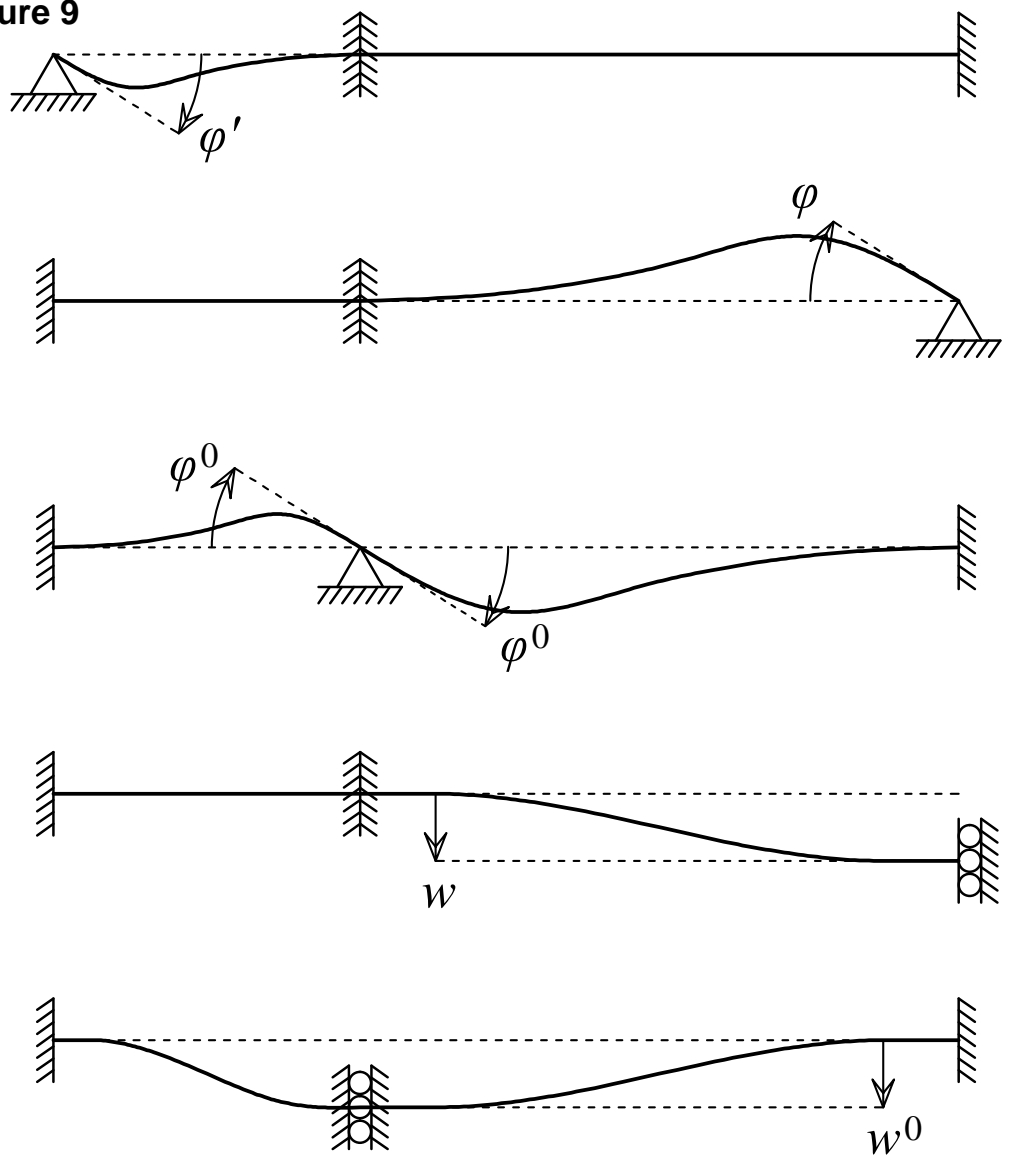

Displacement mode 1

Displacement mode 2

Displacement mode 3

Displacement mode 4

Displacement mode 5 
Figure 10

$\stackrel{N}{\leftarrow}$

$M^{\prime}$
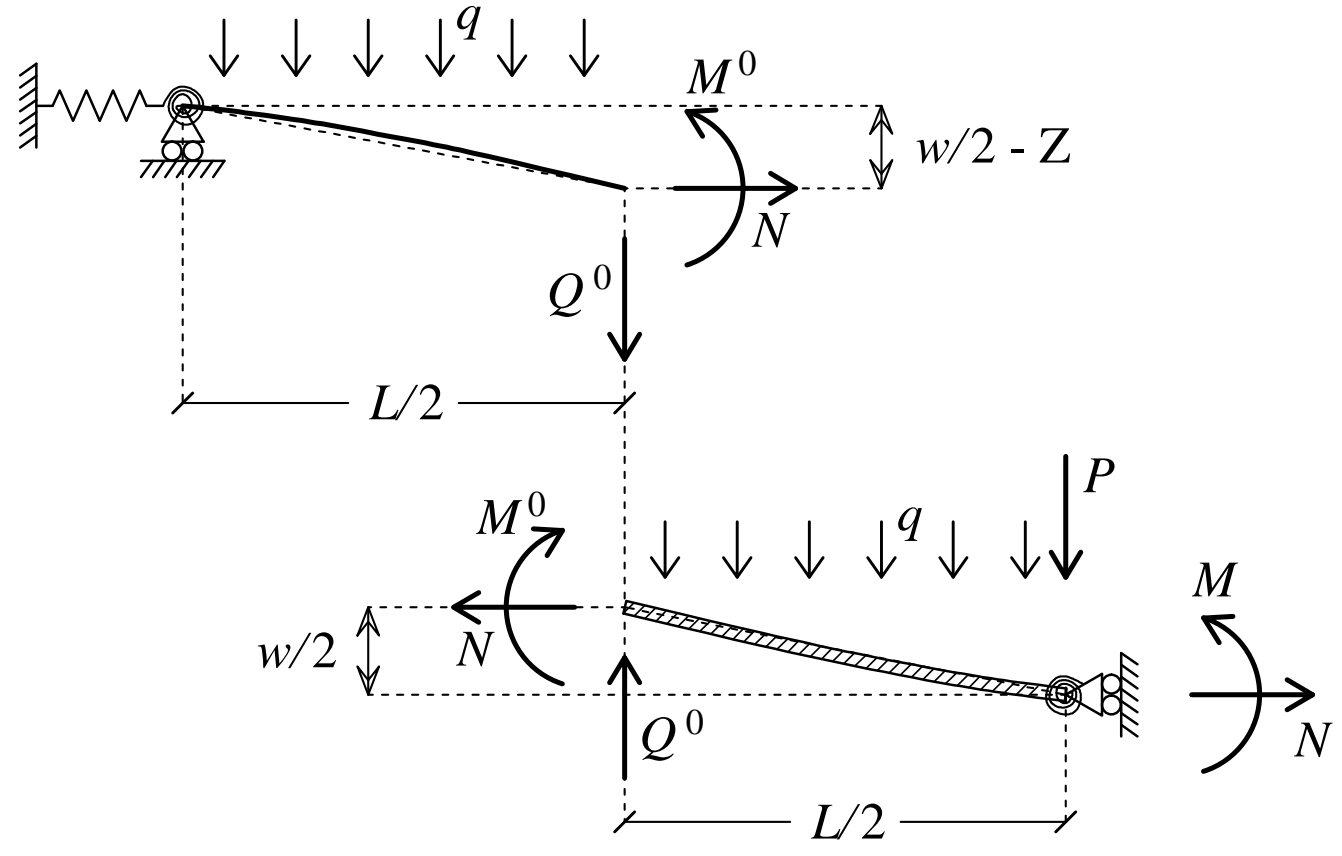


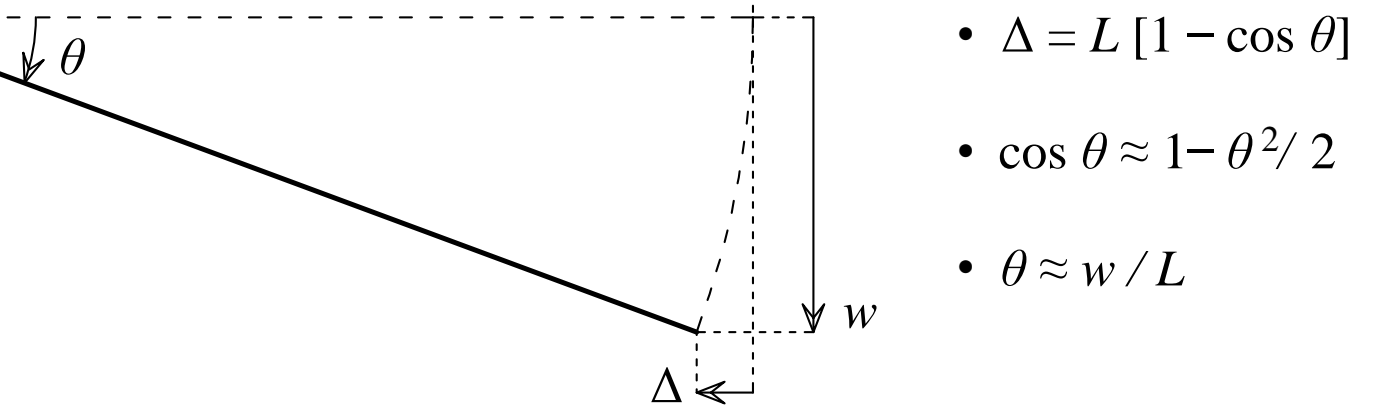


Figure 13

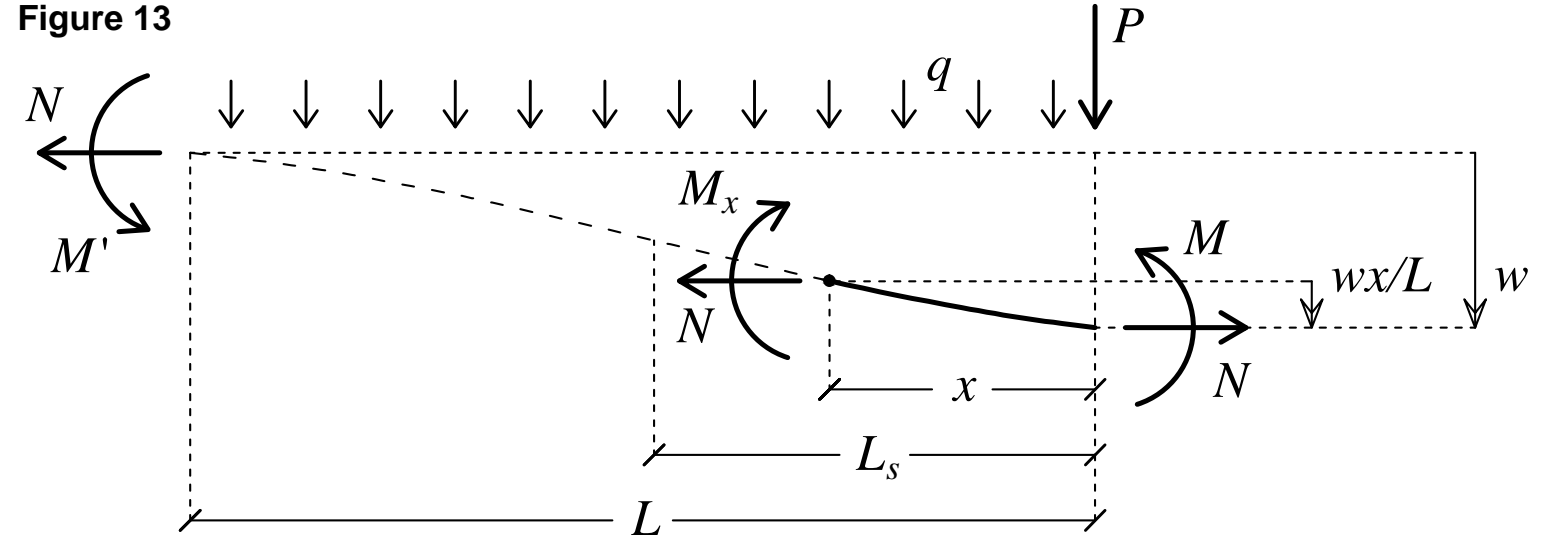

$\downarrow \downarrow \downarrow \downarrow \downarrow \downarrow \downarrow \downarrow \downarrow \downarrow \downarrow^{q} \downarrow \downarrow \downarrow \downarrow$
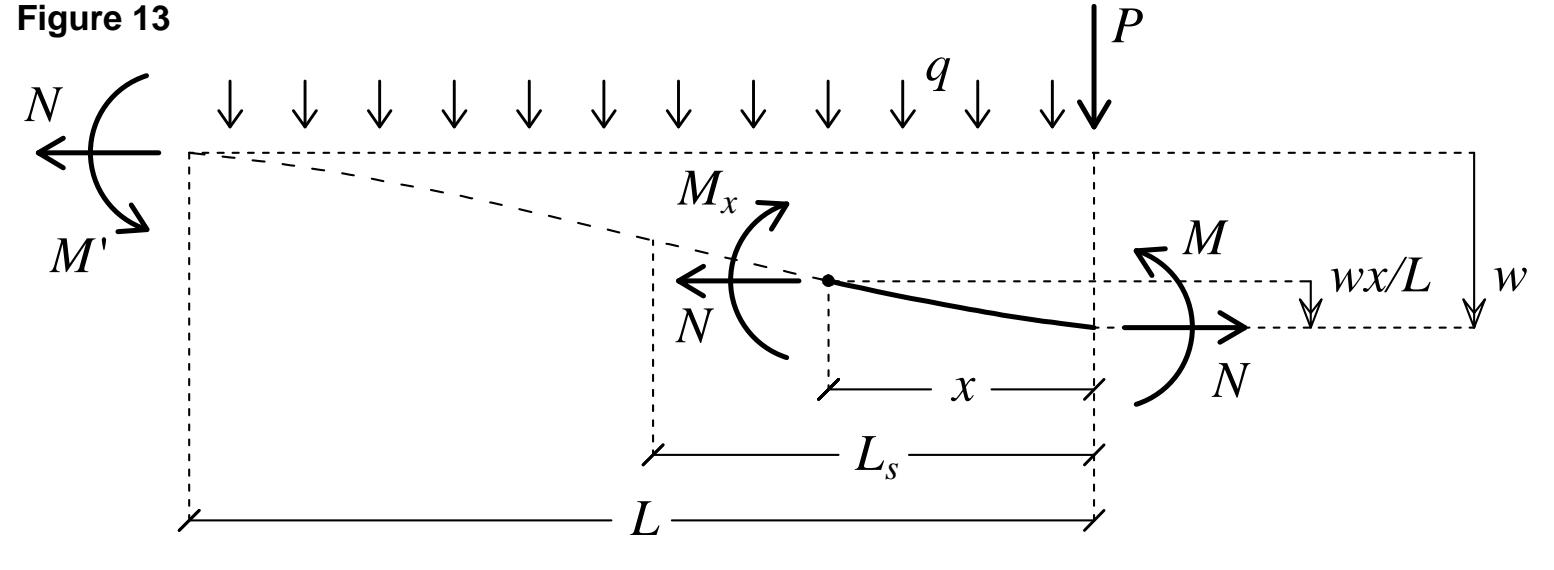

$\mathfrak{R}_{-y^{2}}^{M} w x / L$ $\downarrow^{w}$ $N$

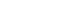

$$
\text { - }
$$


Support

connection
Mid-span connection
Removed

column
Beams: UB $406 \times 140 \times 39$

Columns: UC $305 \times 305 \times 118$ 
Bøørthdary spring

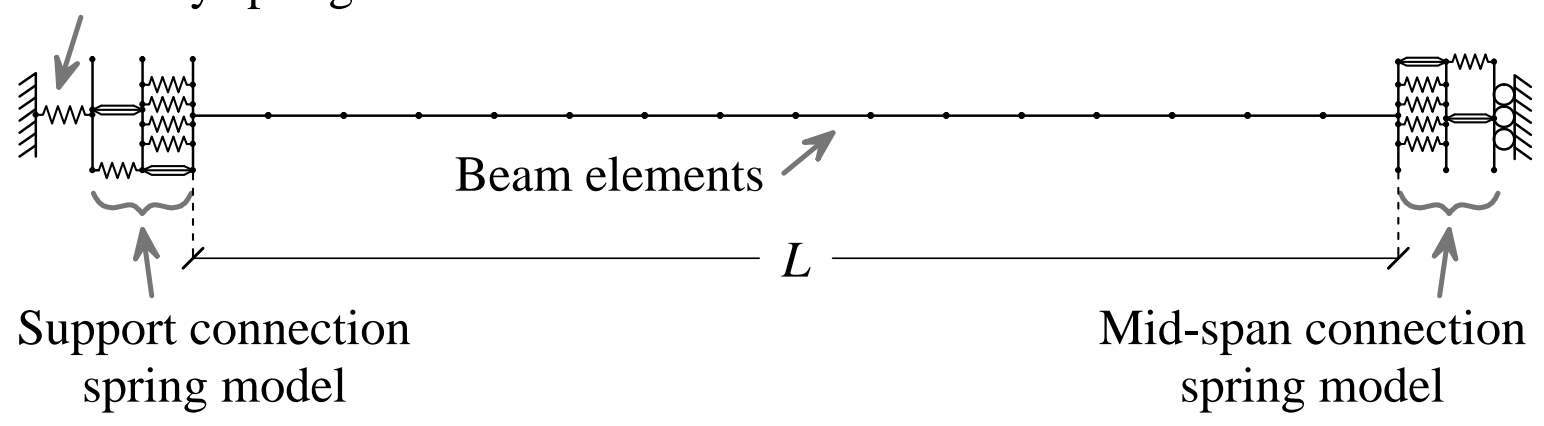

(a) Bare steel
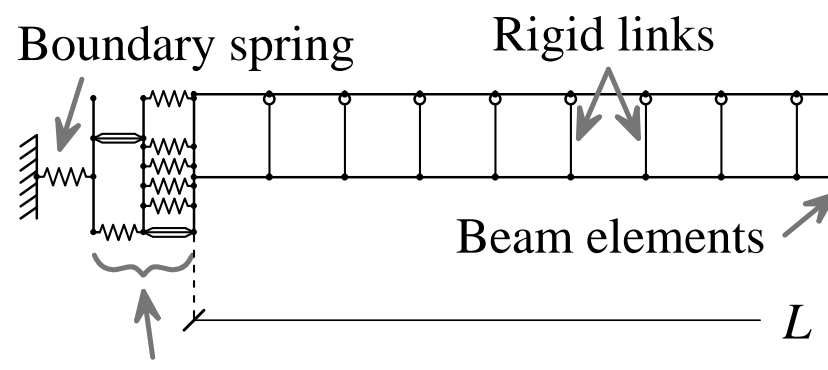

Support connection

spring model

Concrete flange 


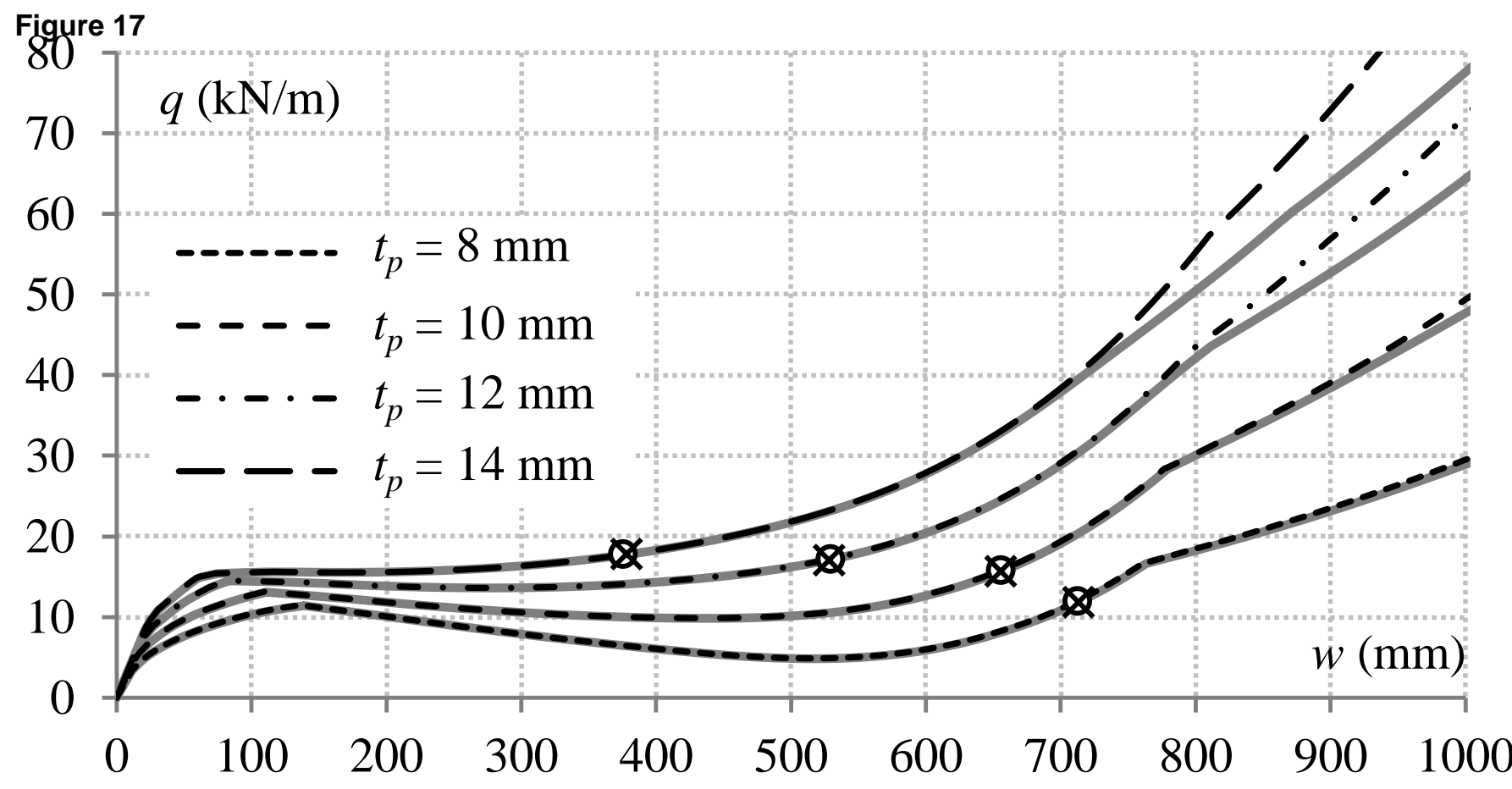

(a) Bare steel beams with various connection endplate thicknesses $(L=6 \mathrm{~m})$

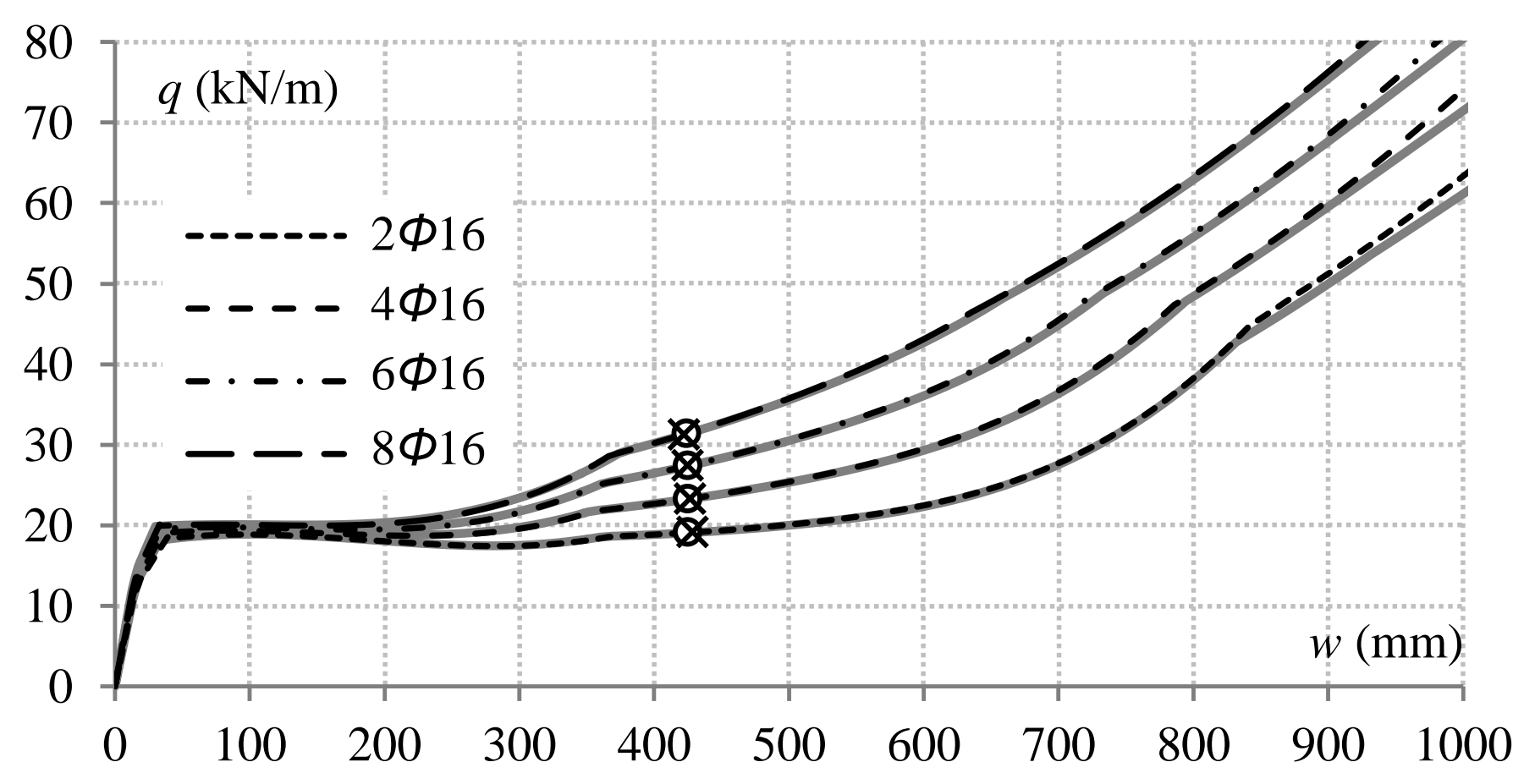

(c) Composite beams with various amounts of reinforcement $\left(L=6 \mathrm{~m}, t_{p}=10 \mathrm{~mm}\right)$

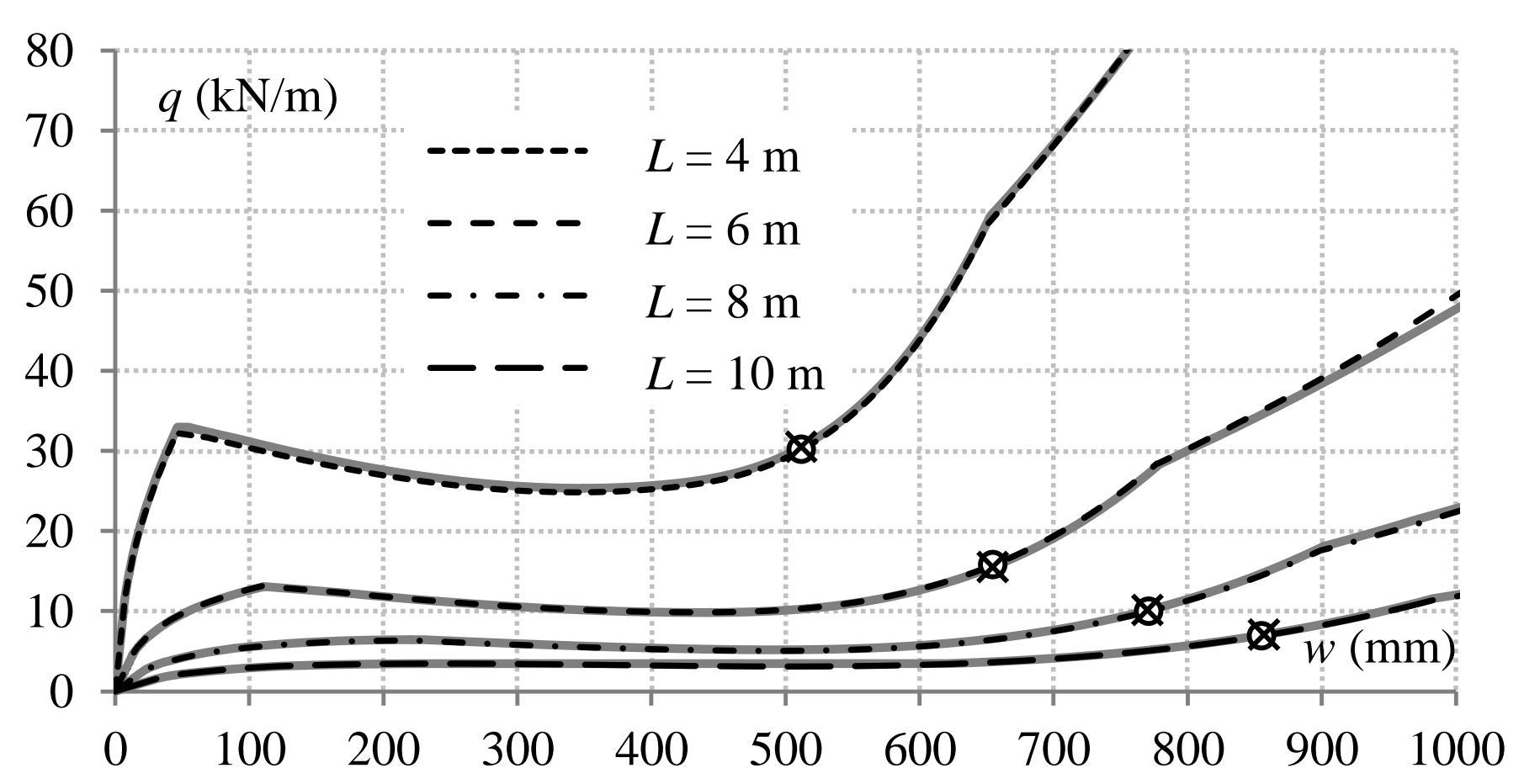

(b) Bare steel beams with various span lengths $\left(t_{p}=10 \mathrm{~mm}\right)$

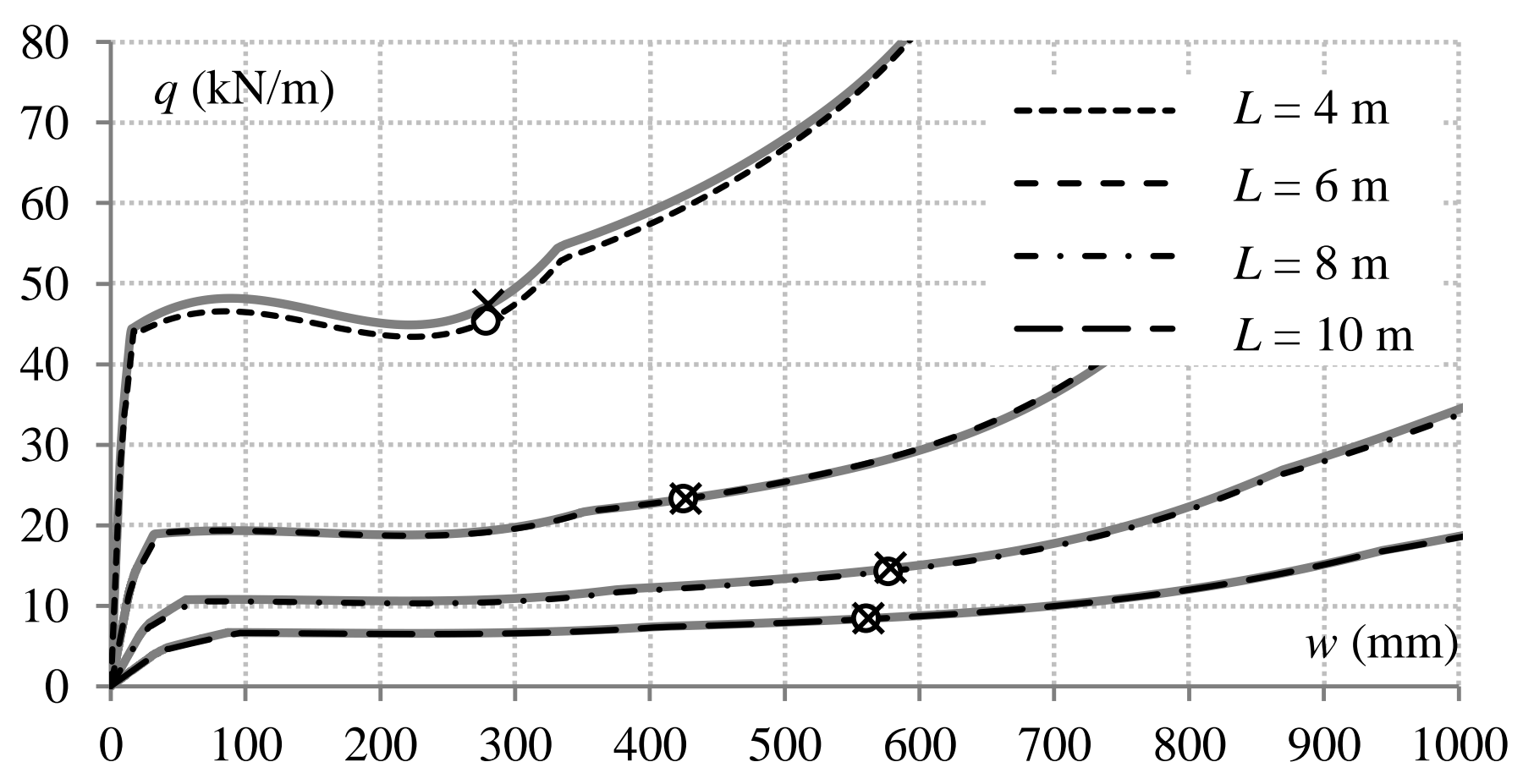

(d) Composite beams with various span lengths $\left(t_{p}=10 \mathrm{~mm}\right.$, rebar $\left.4 \Phi 16\right)$
ADAPTIC
Dashed curves: Analytical method
$\times$ Failure defined by ADAPTIC
- Failure defined by analytical method 

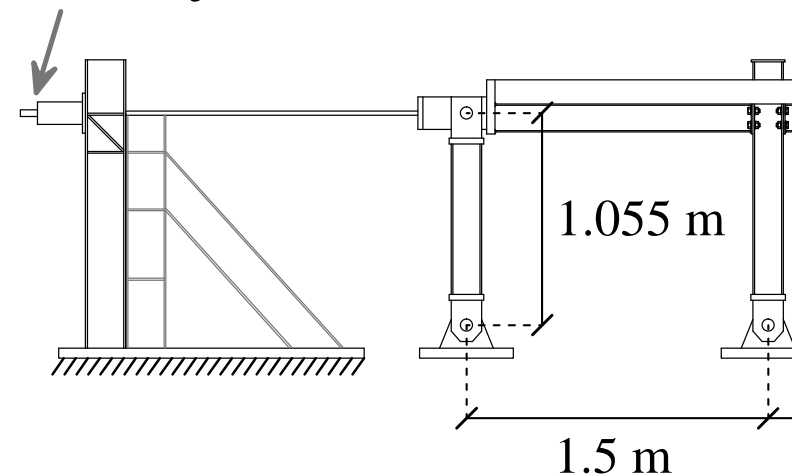

$\sqcap$

\section{Horizontal jack}

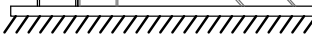

$1.5 \mathrm{~m}$

$4.0 \mathrm{~m}$

$1.5 \mathrm{~m}$

(a) Substructure test configuration

Adjacent frame

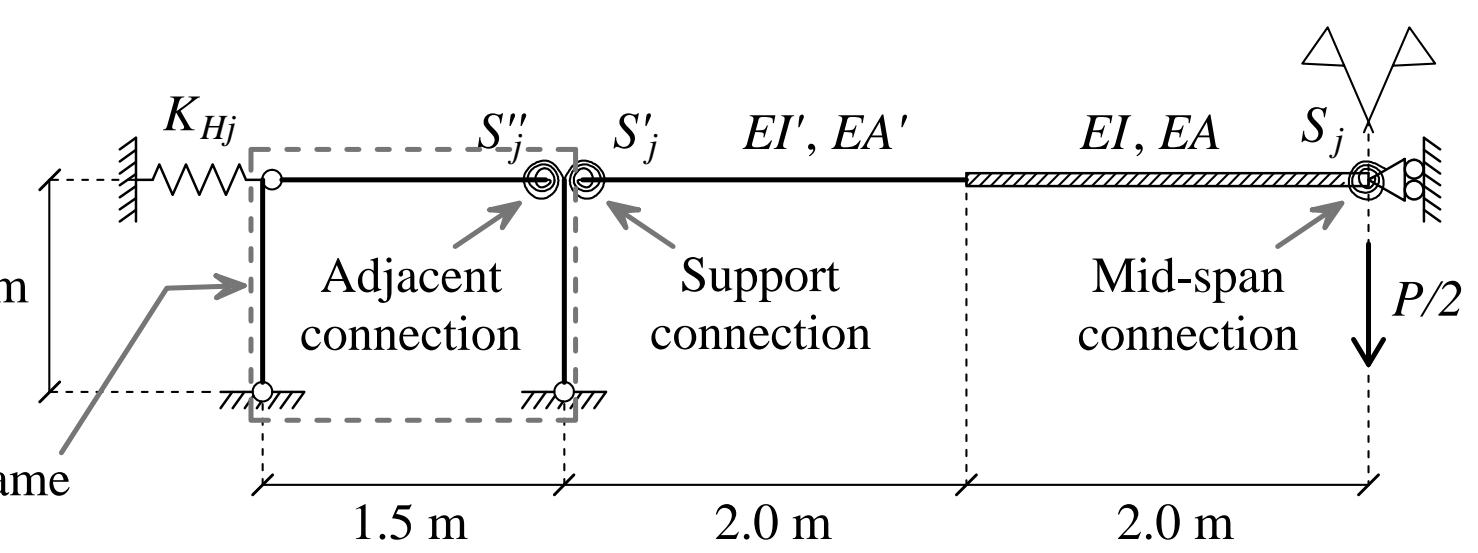

(b) Modelling of axial restraint

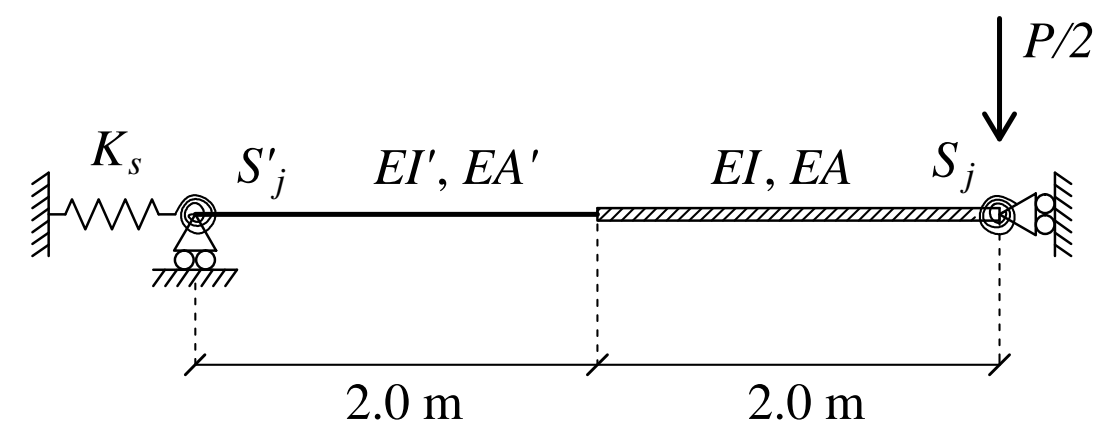

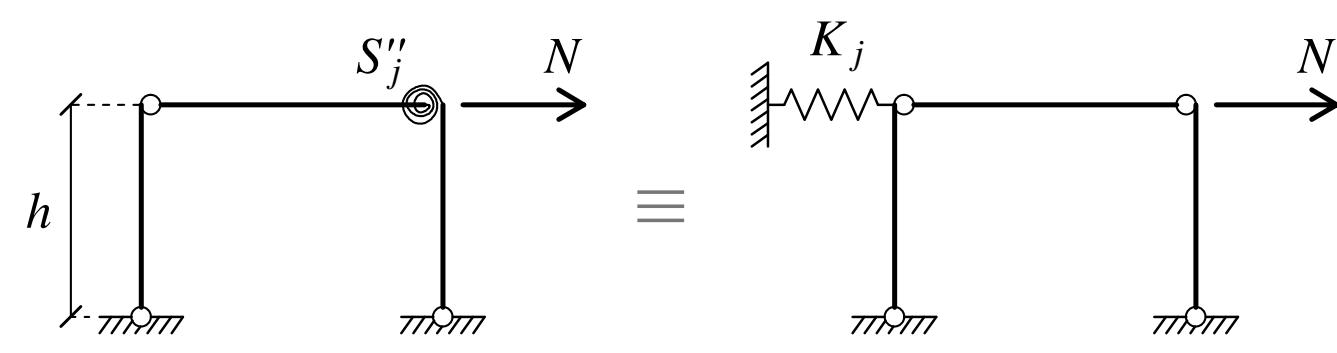

Axial stiffness provided by the adjacent frame: $K_{j} \approx S_{j}^{\prime \prime} / h^{2}$

(c) Simplified structural representation

Total axial stiffness provided by the horizontal jack and the adjacent frame: $\quad K_{s}=K_{H j}+K_{j}$ 


\section{Figure 20}

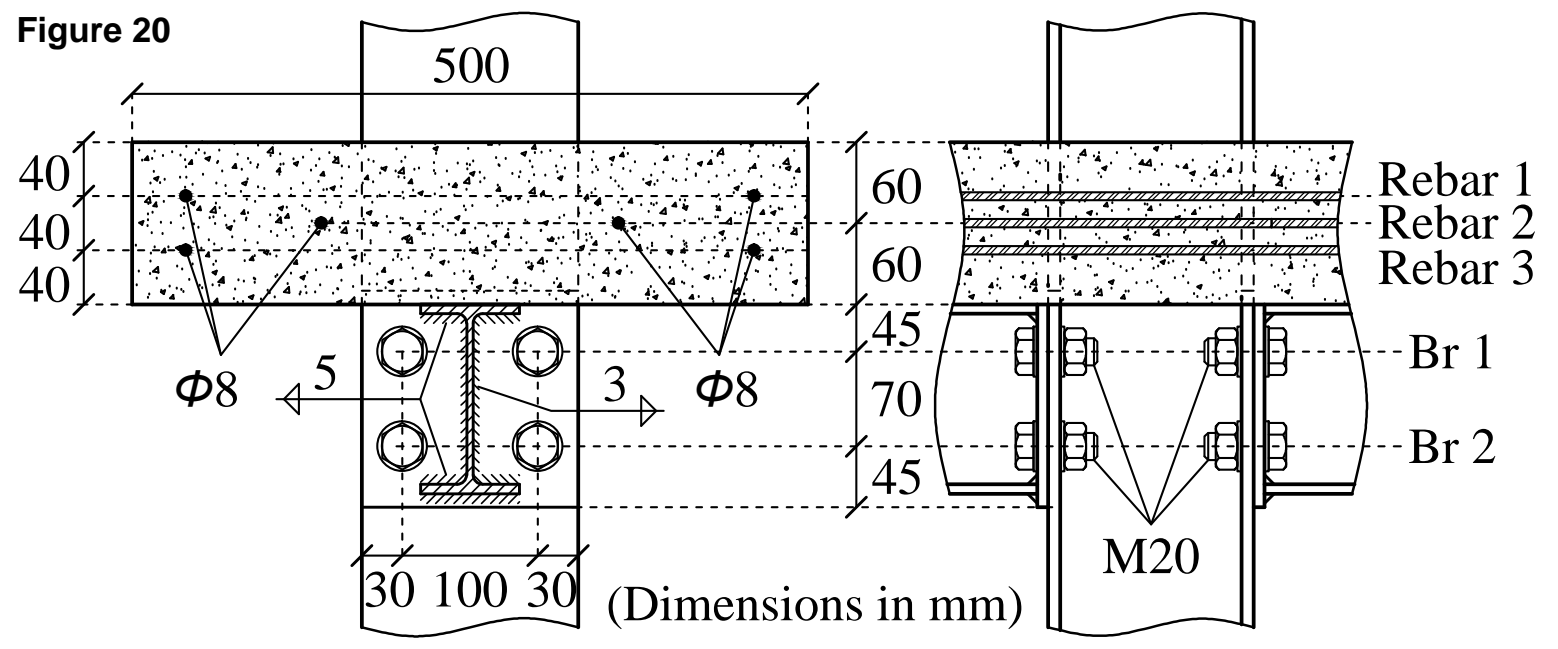

Beams: IPE 140 ; Columns: HEA 160 ; Endplates: $160 \times 160 \times 8$ 
Table 1

\section{Table 1}

Mechanical properties of connection bolt-rows

\begin{tabular}{llll}
\hline $\begin{array}{l}\text { Endplate } \\
\text { thickness }(\mathrm{mm})\end{array}$ & Bolt-row & $\begin{array}{l}\text { Design resistance } \\
(\mathrm{kN})\end{array}$ & $\begin{array}{l}\text { Elastic stiffness } \\
(\mathrm{kN} / \mathrm{mm})\end{array}$ \\
\hline 8 & Br 1 & 66.1 & 261.6 \\
& $\mathrm{Br} 2$ & 34.4 & 141.5 \\
& $\mathrm{Br} 3$ & 34.4 & 141.5 \\
& Br 4 & 64.3 & 255.1 \\
\hline 10 & Br 1 & 103.2 & 470.5 \\
& Br 2 & 53.8 & 264.0 \\
& Br 3 & 53.8 & 264.0 \\
& Br 4 & 100.5 & 459.8 \\
\hline 12 & Br 1 & 148.7 & 720.2 \\
& Br 2 & 77.4 & 425.5 \\
& Br 3 & 77.4 & 425.5 \\
& Br 4 & 144.7 & 705.6 \\
\hline 14 & Br 1 & 183.7 & 974.9 \\
& Br 2 & 105.4 & 613.0 \\
& Br 3 & 105.4 & 613.0 \\
& Br 4 & 182.3 & 958.0 \\
\hline
\end{tabular}


Table 2

Table 2

Mechanical properties of connection reinforcement

\begin{tabular}{llll}
\hline $\begin{array}{l}\text { Rebar } \\
\text { amount }\end{array}$ & $\begin{array}{l}\text { Design resistance } \\
(\mathrm{kN})\end{array}$ & $\begin{array}{l}\text { Elastic stiffness } \\
(\mathrm{kN} / \mathrm{mm})\end{array}$ & $\begin{array}{l}\text { Deformation } \\
\text { capacity }{ }^{\mathrm{a}}(\mathrm{mm})\end{array}$ \\
\hline $2 \Phi 16$ & 176.2 & 212.4 & 7.0 \\
$4 \Phi 16$ & 352.3 & 424.7 & 13.2 \\
$6 \Phi 16$ & 528.5 & 637.1 & 13.8 \\
$8 \Phi 16$ & 704.7 & 849.5 & 14.2 \\
\hline
\end{tabular}

${ }^{\mathrm{a}}$ Corresponding to $6 \mathrm{~m}$ span. 
Table 3

\section{Table 3}

Deformation capacities of the most critical bolt-rows

\begin{tabular}{lll}
\hline Endplate thickness & \multicolumn{2}{l}{ Deformation capacity $(\mathrm{mm})$} \\
\cline { 2 - 3 }$(\mathrm{mm})$ & $\begin{array}{l}\text { Support connection }- \\
\text { Bolt-row 1 }\end{array}$ & Mid-span connection - \\
& 31.8 & Bolt-row 4 \\
\hline 8 & 27.3 & 32.0 \\
10 & $18.8^{\text {a }}$ & 27.4 \\
12 & $10.3^{\text {a }}$ & $19.7^{\text {a }}$ \\
14 & & $10.7^{\text {a }}$ \\
\hline
\end{tabular}

${ }^{a}$ Limited by the tensile resistance of the bolts 
Table 4

\section{Table 4}

Stiffness of axial support

\begin{tabular}{lllll}
\hline \multirow{2}{*}{$\begin{array}{llll}l \\
(\mathrm{~m})\end{array}$} & \multicolumn{2}{l}{$K_{s}(\mathrm{kN} / \mathrm{mm})$} & \multicolumn{2}{l}{ Composite frame } \\
\cline { 2 - 5 } & \multicolumn{2}{l}{ Bare steel frame } & Compressive & Tensile \\
\cline { 2 - 5 } & Compressive & Tensile & 301 & 250 \\
\hline 4 & 261 & 221 & $187-228^{\mathrm{b}}$ & $166-197^{\mathrm{b}}$ \\
6 & 174 & $143-165^{\mathrm{a}}$ & 151 & 137 \\
8 & 131 & 120 & 121 & 111 \\
\hline
\end{tabular}

${ }^{\mathrm{a}}$ Depending on the endplate thickness

${ }^{\mathrm{b}}$ Depending on the amount of reinforcement 
Table 5

\section{Table 5}

Mechanical properties of the connection tensile components [20]

\begin{tabular}{llll}
\hline Component & $\begin{array}{l}\text { Design resistance } \\
(\mathrm{kN})\end{array}$ & $\begin{array}{l}\text { Elastic stiffness } \\
(\mathrm{kN} / \mathrm{mm})\end{array}$ & $\begin{array}{l}\text { Post-limit stiffness } \\
(\mathrm{kN} / \mathrm{mm})\end{array}$ \\
\hline Rebar row $i$ & 54.3 & 264.6 & 5.3 \\
Bolt-row 1 & 144.4 & 118.7 & 5.8 \\
Bolt-row 2 & 144.4 & 100.1 & 5.7 \\
\hline
\end{tabular}

